Cindy Malachowski

University of Ontario Institute of Technology,

Canada

\section{Christina Skorobohacz}

Independent Researcher, Canada

\section{Elaine Stasiulis}

University of Toronto, Canada

Dol: https://doi.org/10.18778/1733-8077.13.4.04

\section{Institutional Ethnography as a Method of Inquiry: A Scoping Review}

Abstract The purpose of this scoping review is to examine the extent, range, and nature of the use of institutional ethnography (IE) as a method of inquiry in peer-reviewed journal publications. Fifteen databases were searched between the years of 2003 and 2013. Relevant data were extracted from 179 included articles.

Findings relate to nine key areas including year of publication, authorship and geography, types of journals, format of resources, authors' descriptions of how they used IE, approaches used in conjunction with IE, data collection methods, standpoint, and institutional relations. Institutional ethnography was diversely conceptualized as: a (sociological) method of inquiry, methodology, research approach, feminist sociology, theory and methodology, framework, lens, field, perspective, and form of analysis. Inevitably, authors applied IE differently across their research and writing, ranging from direct usage or close adherence to IE in a comprehensive manner; to indirect usage or loose adherence to IE by drawing on it as inspiration, guidance, or influence; or borrowing from a certain facet of IE such as a particular theory, concept, method, tool, or analytic strategy. Additionally, some authors adapted IE to suit a specific purpose, which entailed using modified versions of IE to fit a given context or objective, while others strived to extend existing understandings of IE through critique, explanation, review, elaboration, or reflection.

The results from this study are useful to both beginning and experienced institutional ethnographers, as the insights gained provide clarity about the use of IE, identify trends in its application, and raise additional questions.

Keywords Institutional Ethnography; Method of Inquiry; Scoping Study; Standpoint; Institutional Relations
Cindy Malachowski, BKin, BHScOT, MScRehab, $\mathrm{PhD}$, is an adjunct faculty member in the Department of Health Science at the University of Ontario Institute of Technology. She is also an occupational therapist and a certified Psychiatric Rehabilitation Practitioner, with over ten years of clinical experience in a variety of mental health settings. Her current portfolio includes qualitative research approaches to better understand workplace mental health, work disability prevention, and return to work practices for mental health issues.

email address: cindy.malachowski@uoit.ca

Christina Skorobohacz is a researcher, writer, and small business owner who lives in Ontario, Canada. She provides proofreading, content creation, and transcription

$\mathrm{D}$

veloped by Canadian sociologist Dorothy Smith (1987; 1990; 1996; 2003; 2005; 2007; 2008), institutional ethnography (IE) is an established, formal, empirically based, and scholarly alternative sociology (Mykhalovskiy and McCoy 2002). Dorothy Smith's (2005:1) seminal text Institutional Ethnography: A Sociology for People "explicates institutional ethnography as a sociology that translates that concept into a method of inquiry" with distinct ontological orientations, theoretical influences, and guiding concepts. At its core, IE uncovers the social organization of knowledge through its materialist method for mapping out what happens to people, and operates under the assumption that social organization occurs through texts (Campbell and Gregor 2002).

Institutional ethnography uncovers and attempts to help others understand the relations that orga- services to diverse clients. Christina holds 3 degrees from Brock University including a Bachelor of Arts in Child and Youth Studies, a Bachelor of Education, and a Master of Education in Curriculum Studies. She enjoys collaborating with others and engaging in student advocacy work.

email address: cskorobohacz@gmail.com

Elaine Stasiulis, MA, PhD (c) is a Research Fellow at the Hospital for Sick Children and a doctoral candidate at the University of Toronto. Her work involves an extensive range of qualitative research approaches, including institutional ethnography, and participatory arts-based health research projects with children and young people experiencing mental health difficulties and other health challenges.

email address: elaine.stasiulis@mail.utoronto.ca

nize individuals' experiences, and is based on the notion that people participate (both knowingly and unknowingly) in processes of organization of their lives (Smith 1987; 1990; 1996; 2005). This feminist inspired "sociology for people" requires a move in thinking towards what Dorothy Smith (2005:209) has called "the ontology of the social...; meaning that what institutional ethnography is aiming to discover really happens or is happening, and it can be explored and explicated."

Grounded in a Marxist-feminist approach (Smith 1996), Dorothy Smith rejects the dominance of theory and takes up "standpoint" as an orienting concept guiding the inquiry. Her use of "standpoint" serves as a point of entry into the social that "does not subordinate the knowing subject to objectified forms of knowledge of society" (Smith 2005:10). IE 
"is a method of inquiry that works from the actualities of people's everyday lives and experiences to discover the social as it extends beyond experience" (Smith 2005:10).

“Institution" in an institutional ethnographic sense does not denote a physical organization or an establishment such as a school or hospital, but rather serves as an abstract reference to an embodied complex of "ruling relations that are organized around a distinctive function such as education, health care and so on" (Smith 2005:225). Organized by texts, ruling relations are the complex practices that coordinate people's actions locally and "translocal$l y$ " in ways that people are often not fully aware of (DeVault and McCoy 2006). Although the ethnographic research may begin with their experiences within an institutional setting, people's experiences are not the objects of inquiry; rather, aspects of the institution that are pertinent to the organization of people's experiences comprise the focus of the investigation (Smith 2005). The institutional dimension of institutional ethnography guides the researcher's analytic move from the local ethnographic description to the explication of the ruling relations that coordinate people's knowledge and activities (Rankin and Campbell 2009).

The inspiration for this scoping study emerged from our (the three authors') individual experiences applying IE as a method of inquiry within our own research projects. Despite coming from different disciplinary backgrounds and academic settings, we share the belief that IE is being utilized with increasing frequency, and is taken up in varying ways. We also recognize the existence of debates and dif- fering perspectives regarding the methods and approaches that are more or less congruent with IE. The purpose of this review is to apply Arksey and O'Malley's (2005) scoping study methodology to explore the extent, range, and nature of the use of institutional ethnography (IE) as a method of inquiry by systematically mapping various features of IE publications from peer-reviewed literature.

To accomplish the aforementioned objective, we identify key concepts, approaches, and methods employed by institutional ethnographers. Our aim is to establish the types of IE research published, and to provide an overview of how IE has been applied. In doing so, this study will build upon existing understandings of this method of inquiry, highlighting key trends, questions, and gaps. To our knowledge, this is the first comprehensive review of the use of IE on an international scale. Recently, an occupational therapy-specific IE scoping study was published in a non-blind, peer-reviewed professional magazine (Carrier and Prodinger 2014). A largescale review such as the one we have undertaken is important, as it records a vital part of IE history and chronicles the method as it has spread globally and across disciplines. Understanding how IE is being conceptualized, employed, and written about can inform professional and scholarly institutional ethnographic practices, identify notable tensions, and signal avenues for continued exploration. Moreover, it may reassure novice institutional ethnographers to know that others encounter similar challenges and questions, and support their grasp of relevant orienting concepts and methods. Our intention for this study is to encourage scholars, researchers, and other IE practitioners to find supportive spaces and opportunities to make meaningful contributions within the diverse and vibrant institutional ethnographic community.

The scoping review method is congruent with our quest to understand the varied usages of IE. Both scoping reviews and institutional ethnographies (a) recognize mapping as a useful analytical device, although how they employ mapping differs (e.g., Arksey and O'Malley 2005; Smith 2005); (b) utilize similar terminology to label their approach to analysis, such as "descriptive analytical' method" (as stated by Arksey and O'Malley 2005:26), and "analytic description" (as stated by S. Turner, personal communication, June 17-24, 2011); and (c) receive calls from the research community to make the details of their analytic processes visible and accessible to others (e.g., Levac, Colquhoun, and O’Brien 2010; Walby 2013).

\section{Methodology: Process Challenges of Conducting an IE Scoping Study}

This scoping study follows the protocol set forth by Arksey and O'Malley (2005), incorporating the recommendations for enhancing the methodology suggested by Levac and colleagues (2010). Moving through the six stages of this framework (as described later in this section), we summarize features of studies included in the review, and organize key characteristics systematically. The irony of categorizing and organizing the content of IE studies is not lost on us. There are inherent tensions in applying a primarily quantitative method that relies on "arbitrary and reductionist categorizations to explore qualitative research" (O'Shaughnessy and Krogman 2012:504). We would be remiss, if we did not openly acknowledge some of the challenges and incongruities that surface and share our strategies for reconciling these differences.

Specifically, the work of conducting a scoping study involves coding, categorizing, and reduction (Arksey and O'Malley 2005), which contrasts with how institutional ethnographers do research (Campbell and Gregor 2002). For example, we found it challenging to code or categorize complex, multi-dimensional information central to institutional ethnographies, such as "standpoint." Campbell and Gregor (2002:16) state that IE "takes the standpoint of those who are being ruled." Identifying and retaining a standpoint is critical to the practice of IE (Smith 2005; Bisaillon 2012). It is an orienting concept that gets at the intricacy of people's multi-layered or intersecting identities, which shapes how they see and understand the world. To depict the range of standpoints across the articles, we chose a visual mapping schema (Word Cloud) reflective of a mode of description and analysis that is more in keeping with institutional ethnography than a quantitative representation of standpoint such as a numerical table. Institutional ethnographic work is critical of institutional forms of power that tend to "objectify" complex people through the use of narrow, inflexible categorizations (Smith 2005). In the spirit of preserving human diversity and utilizing inclusive language, we are mindful that the people whose perspectives and experiences form the "starting point" for the research (Bisaillon 2012:619) are more than the labels often ascribed to them.

Designing our data extraction chart, drafting the manuscript, and attending to feedback from 
expert consultants involved an iterative approach to (a) clarify the utility of the findings, (b) contemplate potential reactions from a diverse readership, (c) adhere to the journal's publishing guidelines, and (d) remain committed to preserving our own interests and voices. Ultimately, we sought to strike a delicate balance between integrating orienting concepts from IE, utilizing terminology associated with methods of inquiry, and employing procedures consistent with scoping reviews, which necessitated ongoing negotiation, prioritization, adaptation, and compromise.

As our inquiry evolved, so too did our working protocol. Consideration was given towards project feasibility and complexity, as well as available resources and expertise. We found ourselves supporting Daudt, van Mossel, and Scott's (2013:35) suggestion to "remove the term 'rapidly' and replace it with the need for scoping studies to be done thoroughly and thoughtfully," as this kind of work "take[s] time." Refining multiple iterations of charts, procedures, and operational definitions proved tedious, but necessary, given our requirement to develop a unified language and process. We necessarily modified procedures in an effort to troubleshoot difficulties, set reasonable limits, and maintain momentum. The initially projected 1-year, 2-person side-project turned into a 3-year, 3-person research collaboration.

Our literature search proved challenging; upon consultation with library services, we realized that certain search terms we hoped to include (e.g., mapping, problematic, feminist, and sociology) were extremely broad and would yield numerous false positive results. Thus, we refined our list of terms by utilizing key words identified by authors familiar IE articles (for example, Campbell 2003; Pence and McMahon 2003; Rankin 2009; Bisaillon 2012). Although we originally left certain search parameters open-ended, such as the year and type of source, which is typical practice for scoping reviews (e.g., Pham et al. 2014), after retrieving tens of thousands of hits, we determined that conducting a more focused investigation was in order. Given our resource constraints, we limited our sources to one decade, which mirrored a number of recently conducted scoping reviews (e.g., Redvers et al. 2015; Watson, Zizzo, and Fleming 2015; Webster et al. 2015). The 2003-2013 timeframe was selected because it represents a pivotal decade in the development of IE. Dorothy Smith's seminal text was published in 2005, thus providing us with a period that would reflect the impact of this work; as well as a solid indication of recent trends in, and contemporary usage of, IE. We further restricted our charting to peer-reviewed journal articles, a strategy occasionally employed by other scoping reviewers (Pham et al. 2014). Given the frequent comments we heard from institutional ethnographers (at conferences, in workshops, via feedback, and during informal conversations) of the challenges they face getting their work published in peer-reviewed journals, we opted to explore this rich source as the basis for the review. Our assumption was that authors would likely face similar difficulties navigating the web of ruling relations associated with academic publishing (i.e., journals' specific word count, format, and structure regulations; the peer-review process; and the inevitability of having to explain their work to both IE and non-IE audiences). Peer-reviewed jour- nal publications provided us with fruitful grounds for drawing comparisons. However, journal publications may not always reflect cutting edge, or innovative information in a given field; thus, our scoping review provides only a partial view of how IE has been taken up as a method of inquiry. Nevertheless, we hope that our findings will generate rich discussion and debate.

We followed the five stages of Arksey and O'Malley's (2005:22) framework, which entailed: (a) identifying the research question; (b) locating relevant studies; (c) establishing study selection criteria; (d) charting the data; and (e) collating, summarizing, and reporting results. We also included the optional sixth stage of consulting with experts.

Stage 1 of the framework requires the development of a clear research question that will guide the scope of inquiry (Levac et al. 2010). In seeking to better understand the uptake of IE, we posed the following research question: What does the existing peer-reviewed published literature tell us about the extent, range, and nature of the use of IE as a method of inquiry?

Stage 2 involved identifying relevant studies through a systematic review of the peer-reviewed literature published between January 1, 2003 and October 28, 2013. Specifically, we used (a) the OvidSP search platform in the following five databases: MEDLINE, EMBASE, and EBM Reviews-Cochrane Database of Systematic Reviews, PsycINFO, and ERIC; (b) the EBSCOHost search platform in the following two databases: CINAHL and H.W. Wilson Social Science Abstracts; and (c) the ProQuest search platform in the following eight databases: Arts \& Humanities
Full-Text, Canadian Research Index, PAIS International, Philosopher's Index, ProQuest Social Science Journals, Social Services Abstracts, Research Index, and Sociological Abstracts indexed. To ensure comprehensive coverage of the literature, we also conducted a Summon platform search. Combinations of database-specific and free-text terms were used in the search. All searches contained variations of terms utilized frequently in institutional ethnography, including "institutional ethnography," "ruling relations," "text-mediated," "disjuncture," "visible/ invisible," "social ontology," "shape/shaping," "intertextual/intertextuality," and "organization/organizational."

The search retrieved a total of 9,172 references (including the references that were identified by hand searching IE-related special issues of relevant journals, and reviewing the reference lists of the articles that met our inclusion criteria, as well as a random assortment of 30 journals that were likely to publish IE articles). All references were saved in an Endnote library, which was then used to identify and remove the 2,916 duplicates. The remaining 6,256 unique references were reviewed against the inclusion criteria described below. A total of 5,992 articles were excluded after the title and abstract screening. We retrieved 265 full-text articles against which the inclusion and exclusion criteria were applied. Eighty articles were excluded after the full text screening, and six articles were excluded during data extraction; resulting in a total of 179 included articles that became part of the final review (see: Figure 1 for a Flow Diagram depicting the flow of information through the different phases of the review). 
Figure 1. Flow Diagram of Review.

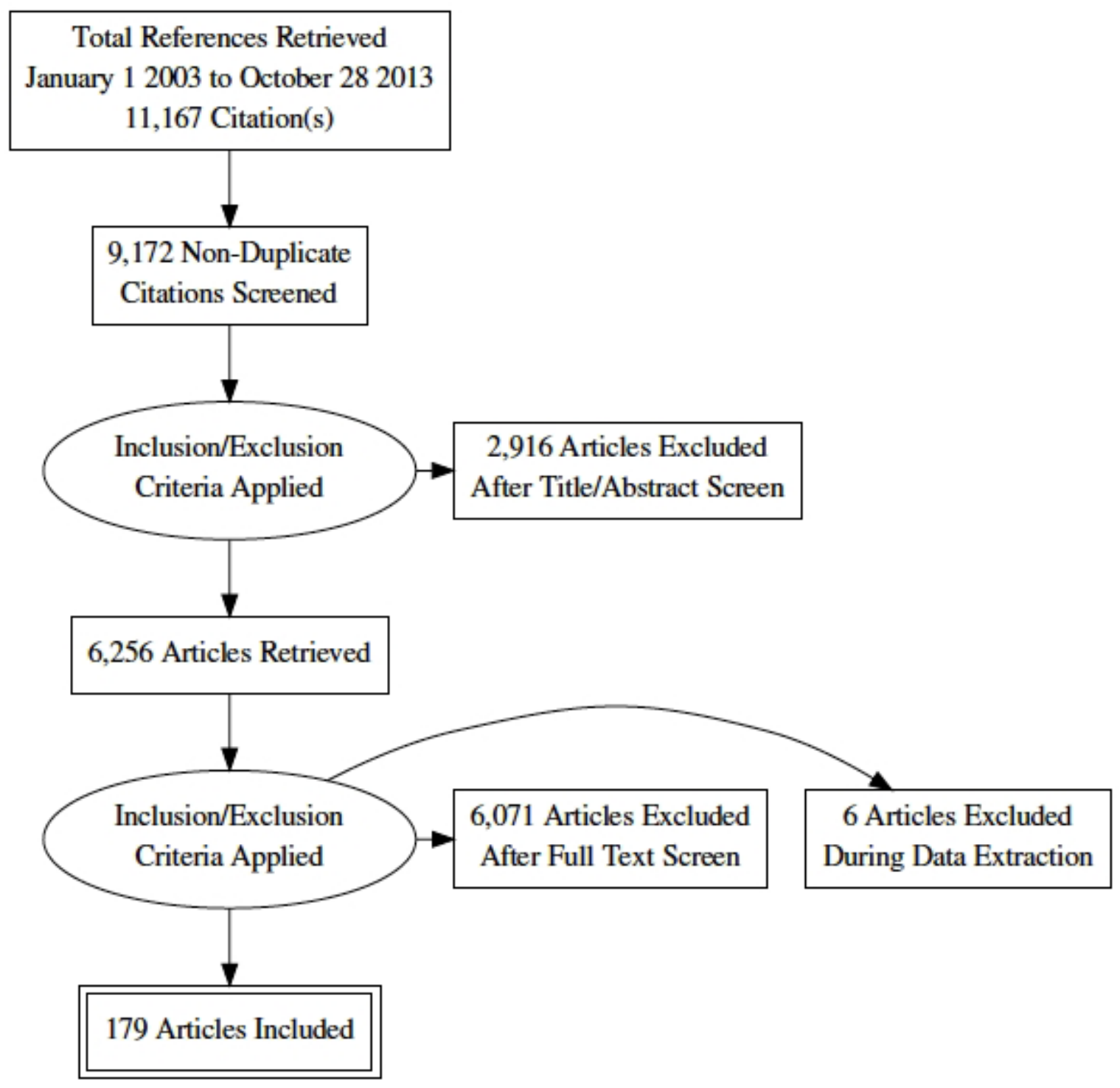

Source: Self-elaboration.

When locating the studies for inclusion during Stage 3, two of the researchers independently reviewed all titles and abstracts for prospective inclusion. The reviewers met at the beginning, midpoint, and final stages of the review process to discuss challenges and refine the search strategy as required. Disagreement arose in relation to nine specific studies; therefore, a third reviewer deter- in journal article format were excluded from the review.

It should be noted that some of the omitted articles appeared to use IE-consistent terminology, approaches, strategies, and sources; yet the authors did not label their work as IE, or acknowledge explicitly that they were drawing on aspects of IE. Other excluded articles made reference to IE, but did not cite Dorothy Smith; thus, these sources were also left out of the review. We maintained a consensus that the inclusion of these basic elements (such as referencing Dorothy Smith's work) were integral and would allow for cross comparison of the included publications.

When charting the data in Stage 4, we utilized an Excel spreadsheet to identify key items of information obtained from the primary source under review. This technique for synthesizing qualitative data included sifting, charting, and sorting material according to the following key categories: year of publication, number of authors, journal of publication, country of primary author, country of co-author(s), geographical location of research/interest, format of resource, author explanations of how IE is being employed in their work, methods of inquiry and other approaches used, data collection methods, standpoint, and institutional relations under investigation. The data chart was refined multiple times in an iterative fashion with the project's purpose and research question in mind to ensure extraction of the information necessary to fulfill the study's objective.

Due to the difficulties inherent in coding such diverse information, we relied on operational defini- tions to standardize the criteria for data extraction. These definitions were generated by reaching consensus, and by applying our own working knowledge and judgment of the key criteria. There were several challenges in extracting relevant data from the articles connected to the divergent uses and intended meanings of IE-related terminology. For example, some authors did not take up a standpoint within their work, while other authors cited multiple standpoints from a variety of perspectives and positions of power. Furthermore, there were some sources that examined numerous institutional relations, or the intersections between them, making categorizing and coding these relations impractical.

After the data extraction stage was complete, information was collated. We recount the comprehensive sense-making process we employed for one specific data column below, in order to provide an example of our methodological and analytic work.

Contents from the data extraction chart column related to "other approaches used" were itemized in list form. Items were then organized into connected clusters. The iterative, messy, and tentative process of grouping related items involved making continuous refinements by readjusting category labels and shifting contents. Various books and online resources were consulted (e.g., Campbell and Gregor 2002; Creswell 2005; 2007; Denzin and Lincoln 2005; Smith 2005; Schwandt 2007) as we operationally defined categories and developed a working understanding of other approaches used in combination with institutional ethnography. Schwandt's (2007) Sage Dictionary of Qualitative Inquiry (3rd ed.) proved to be a particularly valuable source. For a list of our operational definitions, please refer to Table 1. 
Table 1. Operational Definitions for Other Approaches Used with IE.

\begin{tabular}{|l|l|l|l|l|}
\hline \multicolumn{1}{|c|}{ TER M(S) } & \multicolumn{1}{c}{ DEFINITION(S) } \\
\hline Concepts & $\begin{array}{l}\text { A concept "point[s] the inquirer in a general direction but do[es] not give a very } \\
\text { specific set of instructions for what to see" (Schwandt 2007:292). }\end{array}$ \\
\hline $\begin{array}{l}\text { According to Schwandt (2007:292), "a theory is a unified, systematic causal explana- } \\
\text { tion of a diverse range of social phenomena." Schwandt (2007:292) goes on to state } \\
\text { that: "A step up the ladder of sophistication, one finds theoretical orientations or } \\
\text { perspectives (e.g., functionalism, symbolic interactionism, behaviorism...). These, } \\
\text { ophies, or ways of knowing } \\
\text { more or less, are social theories that explain the distinguishing features of social } \\
\text { and cultural life, and thus, they serve as approaches to identifying, framing, and } \\
\text { solving problems, and understanding and explaining social reality." }\end{array}$
\end{tabular}

A methodology or research tradition encompasses: "a theory of how inquiry should proceed. It involves analysis of the assumptions, principles, and procedures in a particular approach to inquiry (that, in turn, governs the use of particular methods)...[It] occupies a middle ground between discussions of method (proce-
Methodologies or research traditions dures, techniques) and discussions of issues in the philosophy of social science...[It]
defines the object of study and determines what comprises an adequate reconstruction of that object" (Schwandt 2007:193).

Some examples of methodologies include: quasi-experimental, survey, ethnomethodology, grounded theory, case study, social phenomenological, ethnographic, naturalistic, and narrative (see: Creswell 2007; Schwandt 2007).

The "activity of making sense of, interpreting, and theorizing data...a variety of procedures that facilitate working back and forth between data and ideas" (Schwandt 2007:6).

Analytic approaches and procedures

Some examples of analytic approaches include: constant comparison method, analytic induction, and grounded theory analysis (Schwandt 2007).

Source: Self-elaboration
Through the process of further (a) consulting multiple original articles to see how authors defined and employed specific approaches, (b) sub-grouping and counting related approaches, (c) eliminating redundant items that were an obvious part of institutional ethnographic or qualitative research practice, and (d) dropping outliers, eight initial categories were distilled to the following three categories:

- Theories, perspectives, frameworks, ways of knowing, guiding concepts, and models;

- Methodologies or research traditions; and

- Analytic approaches and procedures.

Although there were numerous ways that the approaches could have been clustered, the focus of our scoping review (exploring the use of IE as a method of inquiry) directed our gaze to research-oriented categories that would best enable us to answer particular facets of our research question. Each member of the team independently reviewed the draft Table (including its categories and contents) using both operational definitions and expert judgment as a guide. Discrepancies were identified and discussed collaboratively in order to reach an agreement.

Three challenges arose while attempting to categorize approaches. Firstly, some authors provided very general information about the additional approaches they used, while other authors provided very detailed information. When comparing and contrasting available approaches, we realized that multi-leveled groupings would be required to accurately cluster connected items. Secondly, encountering contested terms including contradictory definitions, labels, or understandings within and across the various resources we consulted made it difficult for us to pinpoint within which category a particular item best fits. It became apparent that like institutional ethnography, certain approaches could have easily fit across multiple categories, as they had theoretical, methodological, and analytic underpinnings. In such instances, we strived to place the approach within the category that most closely mirrored how the author(s) defined or used it. Thirdly, there were inherent tensions involved in coding or categorizing these data, as such reductive practices are typically not regarded as consistent with IE approaches to analysis (Campbell and Gregor 2002).

\section{Results}

One hundred seventy-nine peer-reviewed journal articles published between January 1, 2003 and October 28, 2013 were included in the review. Interestingly, between 2003 and 2004, and again between 2006 and 2007 there was a significant drop in IE publications; however, between most other years there was an increase in the number of IE journal articles (see: Figure 2 for details). It is important to remember that IE researchers are also choosing to publish their works in other formats such as books or edited book chapters. Since such sources were excluded from our scoping study, we cannot speak to the broad trends across the diverse landscape of IE literature. 
Figure 2. Number of Publications by Year.

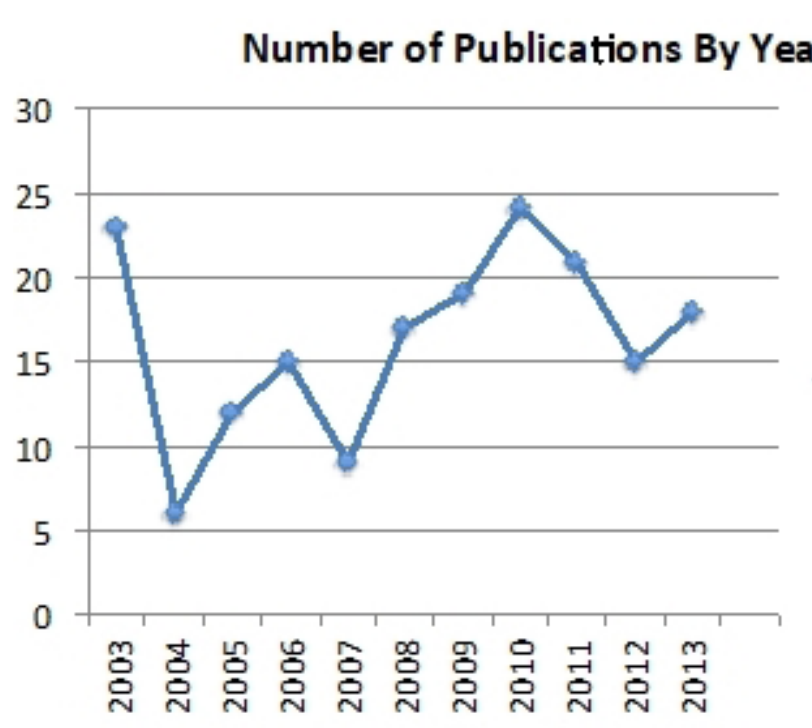

Source: Self-elaboration.

\section{Authors and Geography}

The majority of the publications in the review were single authored papers (93, or 52\%) (e.g., Good-Gingrich 2003; Jung 2003; Mykhalovskiy 2003; Rusted 2006; Walby 2006; Nichols 2008a; Quinlan 2008; Hicks 2009; Fisher 2010; MacKinnon 2010; Bisaillon 2011; Deveau 2011; Murray 2012; Ross 2013). There were fewer publications with large numbers of authors and as the number of authors increased, the number of publications decreased. Specifically, 48 (27\%) of the publications had two authors (e.g., Jakubec and Campbell 2003; Scott and Thurston 2004; Luken and Vaughan 2005; MacKinnon and McIntyre 2006), 19 (11\%) had three authors (e.g., Berkowitz, Belgrave, and Halberstein 2007; Lane, McCoy, and Ewashen 2010; Malinsky, DuBois, and Jacquest 2010; Braaf, Manias, and Riley 2013), 12 (7\%) had four authors (e.g., Sadusky et al. 2010; Marshall et al. 2012; Mumtaz et al. 2012; Moll et al. 2013), and only seven IE publications (4\%) had five or more authors. This trend may reflect discipline-specific publishing practices. For instance, five of the seven papers with the most authors were related to healthcare issues in religious, nursing, midwifery, and occupational therapy contexts (Townsend et al. 2006; Hamilton et al. 2010; Kennedy et al. 2010; MuñozLaboy et al. 2011; Sinding et al. 2012). In healthcare settings, mixed methods are often employed, large inter-institutional investigative teamwork is prevalent, and co-authorship practices that acknowledge the involvement of all stakeholders remain the norm. Another two articles were related to health and transitional issues in educational contexts (Aldinger et al. 2008; Restoule et al. 2013) where collaborations between members of universities, schools, communities, or unit partners frequently occur. Four of the seven articles involved international collaborations. Interestingly, each of these articles had at least one author affiliated with the United States. Other countries represented across the international collaborations included Brazil (Muñoz-Laboy et al. 2011), Canada (Hamilton et al. 2010), China (Aldinger et al. 2008), and England (Kennedy et al. 2010). The remaining two articles involved national collaborations between individuals with Canadian affiliations (Townsend et al. 2006; Sinding et al. 2012).

Primary authors on 150 (or $84 \%$ ) of the articles had North American institutional affiliations. More specifically, 106 (or 59\%) of these articles identified the first author as holding a Canadian institutional affiliation, and 44 (or 25\%) identified the first author as being affiliated with an American institu- tion. Subsequently, first authors on eight (or 5\%) of the articles held institutional affiliations from the United Kingdom, and first authors on seven articles (or $4 \%$ ) had affiliations from Australia. There were five publications (or 3\%) with primary authors from Scandinavia, including Finland (Husso and Hirvonen 2012), Norway (Widerberg 2004), Sweden (Nilsson et al. 2012), and Denmark (Høgsbro 2010). The remaining primary authors were affiliated with institutions in South America-Brazil (Gómez and Kuronen 2011); Africa-Nigeria (McNamara and Morse 2004); or Western-European countries-Austria (Prodinger et al. 2012), Switzerland (Prodinger and Turner 2013), and the Netherlands (Klaver and Baart 2011).

To better understand the geographical location of (a) the research, or (b) interest, we grouped the articles according to Global North and Global South designations. Global North included North America, Western Europe, and developed parts of East Asia; whereas Global South was comprised of Africa, Latin America, and developing Asia, including the Middle East. In total, 14 journal articles (8\%) were based on work completed in the Global South, including research conducted in countries such as Ecuador, Guatemala, Kyrgyzstan, Brazil, Pakistan, Nigeria, and South Africa. Of the 14 articles, only three $(2 \%)$ had first authors from the Global South (one of which was the sole author, while the other two papers had co-authors from the Global North).

\section{Types of Journals and Format of Resources}

Out of the 179 articles, 59 (or 33\%) were published in health-oriented journals (e.g., Paterson,
Osborne, and Gregory 2004; Lynam 2005; McCoy 2005; Winkelman and Halifax 2007; Mykhalovskiy 2008; Limoges 2010; McGibbon, Peter, and Gallop 2010; Rankin et al. 2010; Sinding 2010; Godderis 2011; Veras and Traverso-Yepez 2011; Lowndes, Angus, and Peter 2013; Melon, White, and Rankin 2013), followed by 40 (or 22\%) in sociological journals (e.g., Cleeton 2003; Luken and Vaughan 2003a; 2003b; Knaak 2005; Harrison 2006; Parada, Barnoff, and Coleman 2007; Leonard and Ellen 2008; McNeil 2008), and 15 (or 9\%) in education journals (e.g., Salmon 2007; Comber and Nixon 2009; Hamilton 2009; Nichols and Griffith 2009; Shan 2009; Comber and Cormack 2011; Maher and Tetreault 2011; Comber 2012). The remaining 65 (or 37\%) articles appeared in journals that addressed various facets of policy (e.g., David 2008; Barry and Porter 2012), youth (Pence and McMahon 2003; Kushner 2006a; Nichols 2008b), social work (Kushner 2006b; Hicks 2009; Pozzuto, Arnd-Caddigan, and Averett 2009), aging (e.g., Brotman 2003), law (Goodman 2008), geography (Perreault 2003; McNamara and Morse 2004), agriculture (Tarasuk and Eakin 2005; Eells 2010), ethics (Truman 2003; Fisher 2006a; 2006b), communication (LaFrance and Nicolas 2012), and management (Lund 2012). The Journal of Sociology and Social Welfare was the most prolific publisher of IE articles ( $\mathrm{n}=10$; including a special edition with nine IE publications in 2003); followed by Nursing Inquiry with six publications; and Gender, Work, and Organization with five publications.

The most prevalent formats of papers included empirical research, followed by conceptual papers and experiential pieces. One hundred thirty-one articles $(73 \%)$ were based on empirical research (e.g., 
Townsend 2003; Luken and Vaughan 2006; McCoy and Masuch 2007; MacKinnon 2008; 2011; 2012; Lane 2011; Maher and Tetreault 2011), while 12 articles (7\%) fell into the category of conceptual papers, meaning that IE was utilized to explore issues, and to develop concepts and ideas (e.g., Smith 2003; DeVault 2006; Walby 2013). Cumulatively, the educative resources

(e.g., David 2008; Deveau 2008; Quinlan and Quinlan 2010) and experiential pieces (e.g., Grahame and Grahame 2009; Janik-Marusov et al. 2011; LaFrance and Nicolas 2012) accounted for 22 of the publications (with 11 publications or $6 \%$ each). Refer to Table 2 for operational definitions pertaining to the 7 formats of reviewed resources and their respective percentages.

Table 2. Operational Definitions for Format of Resource.

\section{FORMAT OF RESOURCE}

\section{\#(\%) OF ARTICLES}

Empirical research-draws on data generated from direct and indirect observation(s) or experi-

$131(73 \%)$

ence(s) that are analyzed quantitatively or qualitatively to make a claim

Conceptual-provides explanations and accounts of IE and its development; uses IE as a frame-

work to explore issues, develop concepts and ideas; may draw upon empirical research based on IE approaches to support an argument, but the primary objective is not to report on findings

Educative resource (e.g., toolkit) - provides clarification of, or assistance with, EXISTING the-

ories, concepts, or approaches in order to help others learn how to think, write, or research in a particular way

Experiential account-Relating to, or derived from, experience

Advancing IE theory/methodology/analysis - presents a NEW perspective or practice that al-

ters, modifies, or extends existing work

Literature review - an evaluative report of information found in the literature pertaining to IE

Social critique - a critical analysis, argument, or commentary about contemporary social life, or

social organization, which points out existing flaws, challenges, or problems in society

Source: Self-elaboration.

\section{Authors' Descriptions of How They Used IE}

As IE has evolved and grown exponentially across disciplines, it has been taken up variably (a) as a sole approach/methodology, (b) as a guiding framework or foundation, (c) in combination with other methods, and (d) in other ways that are uncovered later in this review. To get a snapshot of how authors described and used IE, we extracted from the articles the specific phrases related to explanations or descriptions of how authors drew on IE in their work. The phrases were then categorized as indicating one of the following: directly using IE; indirectly or loosely adhering to IE; adapting IE to suit authors' own purposes; extending authors' own and others' understandings of IE; and finally, drawing from IE studies.

Authors mostly described IE as "an approach" (e.g., Yan 2003; Campbell and Teghtsoonian 2010; Mumtaz et al. 2012; Bruch 2013), "a methodology" (e.g., Rankin 2003; Medves and Davies 2005; Parada, Barnoff, and Coleman 2007; McCoy and Masuch 2009), "a method of inquiry or study" (e.g., Brown 2006; Luken and Vaughan 2006; Quinlan 2009), and "a framework" (e.g., McNeil 2005; Traverso-Yepez 2009). In a few instances, IE was referred to as the "work of Dorothy Smith" (e.g., Winfield 2003; Kushner 2006a; Janik-Marusov et al. 2011), including her "feminist sociology" (e.g., Berkowitz and Marsiglio 2007) and "theory of ruling relations" (e.g., Kushner 2006b). It was also described broadly as a "field" (Aldinger et al. 2008), "lens" (e.g., Dyjur, Rankin, and Lane 2011), and "theoretical perspective" (e.g., Townsend 2003).

Direct use of IE was most prevalent in nearly two thirds of the reviewed articles (102 or 57\%) where it was typically employed as the main methodology, or as a framework to examine a body of literature or to reflect on a concept (e.g., Grahame 2003; Adams 2009; King 2009; Baines 2010; Campbell and Kim 2011; Hamilton and Campbell 2011; Krusen 2011; Bisaillon 2013; Lowndes et al. 2013). Indirect use of IE occurred in approximately 43 (or 24\%) of the articles. Phrases such as "based on" (e.g., McGibbon and Peter 2008), "informed by" (e.g., Scott and Thurston 2004), "draws from" (e.g., Tummons 2010), and "shaped by" (e.g., Butterwick and Dawson 2005) suggest that the authors were using only the principles of IE as "inspiration" and "guidance," or only certain aspects of IE in their research or writing, such as a particular concept, method, or form of analysis (e.g., Cormack and Comber 2013; Gerrard and Farrell 2013). Other authors in a smaller subset of articles (11 or 6\%) described using a version of IE such as "multi-sited" (Fisher 2006a), "longitudinal" (Breitkreuz and Williamson 2012), "comparative" (e.g., Sobo, Bowman, and Gifford 2008; Gómez and Kuronen 2011; Muñoz-Laboy et al. 2011), "political activist" (e.g., Bisaillon 2012; Hussey 2012; Bisaillon and Rankin 2013), or "transnational" (Grace 2003). The remaining articles were primarily non-empirical and either (a) extended authors' own and others' understandings of IE (9 or 5\%) through critique (e.g., Walby 2007), explanation (e.g., Deveau 2008; Smith 2008), review (e.g., Kushner 2006a; 2006b), elaboration (e.g., Wittman 2010), or reflection (e.g., Malinsky, DuBois, and Jacquest 2010); or (b) drew from other IE empirical studies ( 5 or $3 \%$ ) for the purpose of substantiating an argument or reflecting on and exploring a particular concept (e.g., Rankin 2009; Marshall et al. 2012). The remaining articles ( 9 or $5 \%$ ) were not applicable for this type of categorization (e.g., David 2008; Bisaillon and Rankin 2013). 


\section{Using IE and Other Approaches}

Of the 179 articles in our scoping study, 100 (or 56\%) appeared to utilize IE exclusively, while 79 (or 44\%) appeared to utilize IE in combination with at least one other theoretical, conceptual, methodological, or analytic approach. Table 3 provides a comprehensive picture of 90 other approaches that were extracted across the 79 sources. Forty-four (or $49 \%$ ) of the 90 approaches constituted various theories, perspectives, frameworks, ways of knowing, guiding concepts, and models; while 30 (or 33\%) were methodologies or research traditions; and 16 (or 18\%) encompassed analytic approaches and procedures.

Authors employed anywhere from 1 to 7 additional approaches, with an average of 1.5 other approaches. The use of 1 other approach was most prevalent across the articles, while the use of 7 other approaches was least prevalent across the articles. Most frequently cited theories that were used or explored in combination with IE included a diverse range of feminist perspectives across 6 of the articles, followed by a symbolic interactionist perspective in 6 of the articles. Most frequently cited methodologies that were used or explored in combination with IE included 9 different types of ethnography across 11 of the articles, 4 types of case study across 7 of the articles, and 2 types of grounded theory across 6 of the articles. Most frequently cited analytic approaches that were used or explored with IE included 2 kinds of discourse analysis across 7 of the articles and thematic analysis across 6 of the articles.

Articles were evenly divided in terms of authors who gave some reasoning for merging other theo- ries, methodologies, or analysis strategies in concert with IE, and authors who did not provide an explanation. Occasionally, more than one rationale for combining various approaches was cited. However, authors employing multiple additional approaches within the same paper or project sometimes only offered a partial justification, describing why one (but not all) of the approaches were utilized. Typical explanations included brief statements suggesting that the combination of approaches enhanced findings by providing the addition of useful "conceptual tools" (Ross 2013), a "more theoretically informed perspective" than is currently available (Butterwick and Dawson 2005), "robust" (Kennedy et al. 2010) or "sensitizing lenses" (Berkowitz and Marsiglio 2007), and particular contexts that IE could not provide on its own, such as historical (Murray et al. 2012) and biographical (Shan 2009). Moreover, the addition of IE (and sometimes other approaches) served as a mechanism for (a) addressing gaps and needs in specific fields (Murray, Low, and Waite 2006; Moser 2009; Bruch 2013), (b) solving problems identified by theorists (Hart and McKinnon 2010), and (c) supporting necessary change (Restoule et al. 2013) through the concretization of strategies, analyses, evaluations, or conclusions with increased specificity, practicality, and utility for actual people (Murray et al. 2006; Moser 2009; Hart and McKinnon 2010; Restoule et al. 2013), and the development of "holistic understanding[s]" surrounding a given process (Murray et al. 2006).

Conversely, other approaches were added to address areas authors claimed that IE alone could not meet, such as making the research accessible by using arts-based methods (Slade 2012), understanding

Table 3. Other Approaches Used or Explored with Institutional Ethnography (IE).

THEORIES, PERSPECTIVES, FRAMEWORKS, WAYS OF KNOWING, GUIDING CONCEPTS, AND MODELS

Actor network theory

Adapted partnership framework (Scott-Taplin)

Autobiographical occasions (Zussman)

Bourdieu's theories and concepts

Forms of capital

Theory of practice

Conceptual frame of policy sociology (Ball)

Critical perspective

Critical realist perspective

Critical success factors

Culture of work enforcement (Piven)

Decision analysis/Risk-analysis models

Decolonial knowledge

Disability

Domains of scholarship (Boyer)

Dualism paradox (Durkheim)

Embodied care (Merleau-Ponty, Bourdieu, Goffman

Feminist perspective(s)

Feminist critical theoretical framework

Feminist materialist intersectionality

Feminist standpoint theory

Intersectionality theory

New and feminist materialisms

On social and gender inequalities

Foucault's theories and concepts

Panopticon metaphor

Power and governmentality (2)

Institutional phase theory

Interorganizational relations theory

Interrogations of an audit culture (Ball and Morley)

Model for the evaluation of rural sustainability

New literacy studies theoretical perspectives

Outsider/within status (Hill-Collins)

Performance and visual culture

Politics and the public sphere (Ardent)

Pragmatism

Symbolic interactionism (6)

Procreative identity framework

Relational psychoanalysis theory

Rhetorical spaces (Code)

Sociology of science theoretical perspectives

Structuralism

Structuration theory from cultural studies

Texts (Titchkosky)

Transgender theories

\section{METHODOLOGIES OR RESEARCH TR ADITIONS}

Anishinaabe (Ojibwe) methodology

Arts-informed research using reader's theatre

"Biomedical technography"

Bourdieuian field analysis

Case study (3)

Extended case method (2)

Collective case study

Comparative case study

Critical qualitative methodologies*

with attention to reflexivity and power

Ethnobotany

\section{Ethnographies}

Activist ethnography

Autoethnography

Critical ethnography

Cross-cultural ethnography

Hospital ethnography

Medical anthropological ethnography

Political activist ethnography* (3)

Psycho-social ethnography of the common-

place method*

Transnational institutional ethnography*

Ethnomethodology

Conversation analysis

Grounded theory (6)

Modified grounded theory

Life history methods

Naturalist approach to sociology

Participatory action research (2)

Feminist participatory research methodology Safety audit methodology 


\section{ANALYTIC APPROACHES AND PROCEDURES}

Constant comparative strategies of concept development Content analysis

Critical social science analytic frame

Crystallization (Janesick)

Discourse analysis (3)

Critical discourse analysis (4)

Historical analysis

Listening guide method of analysis

Narrative analysis (2)

Open and axial coding

Phenomenological analysis

Interpretive phenomenological analysis

Secondary analysis of survey data

Social network analysis including mappings

Standard anthropological text analysis techniques

Thematic analysis (6)

Source: Self-elaboration.

how texts arrived at their locations through Actor Network Theory (Tummons 2010), or enhancing the study of sensitive issues with increased attention to people's emotions and researcher's positioning via a proposed approach called biomedical technography (McGibbon and Peter 2008). Finally, Taber (2010) makes a case for employing autoethnography in her IE study because she could not obtain organizational access to conduct interviews.

Individuals also acknowledged various sources of theoretical (e.g., Nichols 2009), ontological (Satka and Skehill 2011), identity (Bain 2010), representational (Restoule et al. 2013), and design (Moser 2009) inspiration (or influence) that informed their projects, scholarship, or researcher positioning. Specific authors located themselves as being "in the middle of [certain] disciplines," striving to achieve "a balance between [multiple] positions" with the goal of ensuring that findings are of mutual relevance to different groups (Klaver and Baart 2011:691). vided important historical information regarding the origins of political activist ethnography, stating:

Notes. Approaches within each column are presented in alphabetical order. Repeatedly cited approaches are folthe total number of articles across which they were of ployed. Specific subsets of broader approaches (such as ployed. Specific subsets of broader approaches (such as arous ty pes of feminist perspectives, case study methuse of indentations. *Approaches marked with an asterisk were regarded by authors as related to IE.

Importantly, IE was viewed as an ideal companion to other approaches because together, they "support and complement one another" (Daniel 2005) with respect to their "philosophic assumptions" (Kushner 2005); "interpretive nature" (Murray et al. 2012); "standpoints" (Dergousoff 2008); "emphases," "concerns," or "conceptualizations" (Gerrard and Farrell 2013; Restoule et al. 2013); orienting concepts or foci (Moser 2009; Høgsbro 2010); and similar groundings in the study of oppression, marginalization, power, and/or knowledge (Murray et al. 2006; Salazar 2008). Notably, multiple "other" approaches (marked with an asterisk in Table 3) were regarded by authors as either "heavily based on;" "emerging from;" or a "specialized form," "extension," or "expansion" of IE. These interconnected branches comprise political activist ethnography (Bisaillon 2012; 2013; Hussey 2012), psychosocial ethnography of the commonplace method (Gibson, O'Donnell, and Rideout 2007), and transnational institutional ethnography (Grace 2003). One of the experts we consulted pro-
This approach is based on a paper by George Smith called "Political Activist as Ethnographer" which was written and published before the name "institutional ethnography" was invented; yet it can be viewed as an early formulation of IE as an activist approach. [Expert Consultation, October 5, 2015]

IE was also located under the umbrella of critical qualitative methodologies (Bruch 2013).

A few authors provided in-depth rationales for using IE in combination with other tools, particularly when they employed it in concert with the ideas of major theorists such as Michel Foucault, Pierre Bourdieu, and Hannah Arendt (Mykhalovskiy, McCoy, and Bresalier 2004; Nichols 2009; Gerrard and Farrell 2013). Such authors typically pinpointed the opportunities resulting from marrying the approaches, and acknowledged direct implications for their findings. For instance, Mykhalovskiy, McCoy, and Bresalier (2004) articulate:

While Smith's project and Foucauldian work each has its own intellectual specificity, we draw them together as resources that help us to think about power as multiply sited and exercised through relations of knowledge. From this location, our analysis of interviews with people living with HIV, community-based HIV health information and the current biomedical research literature suggests that in the context of HIV much more is at work in people's relationships to treatments and medical advice than the power of medicine over patients. [p. 317]
Likewise, authors juxtaposed approaches for comparative purposes, often outlining the varied contributions to a given field (David 2008); or they troubled (a) taken-for-granted notions such as “Foucault's Panopticon metaphor" (Walby 2005), or (b) researcher identities (Bain 2010) in ways that unearthed complexities and contradictions.

In some cases, authors conveyed Dorothy Smith's criticisms of particular theorists' assumptions (Gerrard and Farrell 2013), and acknowledged the challenges inherent in mixing methodologies that were not aligned with IE's epistemology and ontology (Nichols 2009; Quinlan and Quinlan 2010) and that, in fact, Dorothy Smith viewed IE as a framework for inquiry as opposed to a research methodology (Tummons 2010). However, according to these and other authors, the strength of the commonalities shared between IE and other approaches were enough to balance the disparities in ways that led (or might lead) to innovative, expansive, and clarified methods for examining social phenomena (Mykhalovskiy et al. 2004; Eveline, Bacchi, and Binns 2009; Nichols 2009; Quinlan and Quinlan 2010; Gerrard and Farrell 2013). Ultimately, when attentive to multiple approaches' strengths, shortcomings, and subsequent reworkings (e.g., Husso and Hirvonen 2012) and committed to building "bridges" or "locating intersections" (e.g., Restoule et al. 2013), authors saw themselves as "working with and between" the approaches, conceptualizing each as being "in dialogue with" the other (e.g., Dergousoff 2008; Gerrard and Farrell 2013).

When explicit explanations for using multiple approaches were not obvious, implicit rationales 
could sometimes be surmised from the contextual, content, or procedural clues embedded within the articles. Authors appeared to have chosen a combination of approaches (including IE) to (a) offer a different or extended perspective; (b) advance a case or develop a critique; (c) demonstrate innovation by making new contributions; (d) achieve pragmatic needs or personal desires; (e) support reflection, reflexivity, or participation; (f) provide a way to organize, structure, present, or frame the analysis; (g) draw upon preferred or most familiar research methods; (h) conform with disciplinary or scholarly knowledge, training, or conventions; or (i) adapt to the in-situ challenges encountered over the course of the inquiry.

\section{Data Collection Methods}

The majority of manuscripts (132 or $74 \%$ ) used multiple data collection methods such as interviews, texts, and observations. Twenty-one articles (or 12\%) used only one source of data, and the most frequent single data collection method was interviews. The remaining 24 articles (or 13\%) did not collect data. Additional methods of data collection captured in the "other" category included shadowing, drawing on archival data, gathering community demographics, employing a "think out loud" technique, and incorporating participant journaling. Figure 3 denotes the frequency of the data collection methods used across publications.

Authors of 21 publications appeared to draw on material obtained predominantly through a single method of data collection. More than half of these publications (12 or $57 \%$ ) relied primarily on inter- view data (Harrison 2006; MacKinnon 2006; Murray et al. 2006; Weigt 2006; Berkowitz and Marsiglio 2007; Breitkreuz, Williamson, and Raine 2010; Reimer and Ste-Marie 2010; Husso and Hirvonen 2012; Nilsson et al. 2012; Beck et al. 2013; Haneda and Nespor 2013; Taylor 2013), which is consistent with some claims that interviewing is one of the most commonly used data collection methods in institutional ethnography (DeVault and McCoy 2006). Importantly, some of these authors did situate key issues within an historical context meant to serve as a complement and comparative reference point to their interview data (e.g., Murray et al. 2006). Authors of 3 publications (respectively) drew largely on literature (Folkmann and Rankin 2010; Dyjur et al. 2011; Dale et al. 2013) or texts (Bell and Campbell 2003; de Montigny 2003; Harrison 2012) as their primary data sources, while authors of 2 publications (Butterwick and Dawson 2005; de Montigny 2011) relied on their own experiences as data. Finally, authors of 1 publication (Stooke and McKenzie 2009) used participant observation as their key method of data collection, although informal discussions also occurred during some of their observations.

At first glance, authors' extensive reliance on a single data source in 23 or $13 \%$ of the publications may seem curious considering that multiple and diverse methods of data collection tend to be the norm in IE (Campbell and Gregor 2002). However, a handful of articles were identified as either critical literature reviews or experiential pieces (Butterwick and Dawson 2005; Folkmann and Rankin 2010; Dyjur et al. 2011; Dale et al. 2013), where drawing largely on a single data source seems appropriate. In the case of empirical investigations, the need to adhere to specific word count restrictions requires that authors select only a portion of a larger project to explore, a potentially challenging task for institutional ethnographers, because of the scope and complexity of their work, and of the institutional

relations being explicated. Some authors strategically focused on providing a detailed analysis of a key text, textually-mediated process, or relevant discourse (e.g., Bell and Campbell 2003; de Montigny 2003; Harrison 2012).

Figure 3. Data Collection Methods.

\section{Data Collection Methods}

- Number of publications using method

other

Informal discussion/converstaion 8

Surveys 9

Fieldnotes 12

Literature as data 12

Experience as data $\quad 30$

Focus groups 31

Observation 65

Texts/textual analysis 77

Interviews 120

Source: Self-elaboration.

\section{Standpoint}

In reporting the standpoint of the research, our quest was to preserve and present the messiness and the multi layers of people's lives through the varying locations that authors took up in their work. This notion of standpoint humanizes the starting point of the research and speaks to how IE typically begins from the margins or from the experiences of people located outside the ruling apparatus (Bisaillon 2012); individuals bereft of the authority to make policy or funding decisions, often occupying multiple levels of disadvantage and vulnerability in society. However, accurately categorizing the diverse and varied standpoints across publications proved awkward and unmanageable. Instead, we opted to present the range of standpoints as a word cloud (see: Figure 4 for details). This method provides a general overview and an idea of the most commonly reported standpoints as indicated by the size of font. In our word cloud, "nurses," followed by "occupational therapists," and "people with HIV" were the most prominent, 
suggesting that they were the most frequently cited standpoints. When possible, we maintained the authors' original wording.

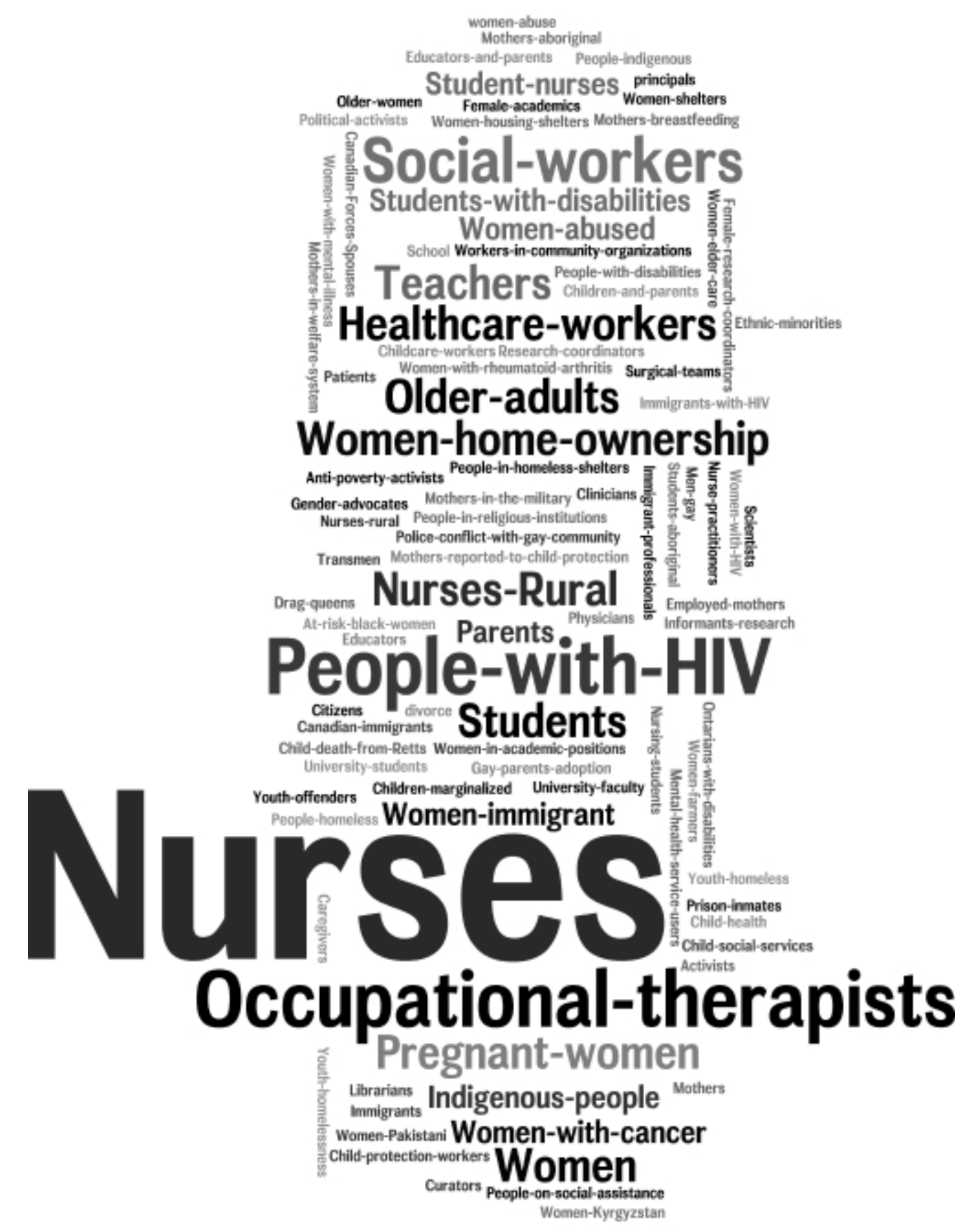

Source: Self-elaboration.
Institutional Relations

Next, we examined the primary institutional relations that were addressed within each publication (see: Table 4 for details). We developed a series of operational definitions based on the results of a qualitative content analysis of reported data. Category clusters were then created to describe the primary institutional relations discussed in each paper, and we subsequently quantified these clusters by counting the number of times each relation occurred across the range of publications. A total of 23 publications were excluded because authors did not examine particular institutional relations, or the papers were deemed to be conceptual (e.g., articles coded as "educative" or "toolkit").

Fifty articles (or 28\%) addressed institutional relations related to healthcare systems, service delivery, diagnosis, treatment, or prevention The next most prevalent institutional relations addressed were educational (in 30 or $17 \%$ of articles), social services (in 26 or $14 \%$ of articles), and governmental (in 22 or $12 \%$ of articles). Interestingly, 16 articles (or 9\%) were classified as exploring "other" institutional relations related to religion, gender mainstreaming, anti-oppressive practices, North American cowboy culture, the discourse of black mothers, research, international development, and housing or home ownership. The remaining relations included community organizing, immigration, humanitarian work, and agriculture.

Table 4. Operational Definitions of Institutional Relations.

INSTITUTIONAL RELATION (OPERATIONAL DEFINITION)

\#(\%) OF

Healthcare-Any relations regarding healthcare systems, healthcare service delivery; or relations related to diagnosis, treatment, or prevention of disease, illness, injury, and other physical and mental impairments

Education-Any relations addressing formal learning in which knowledge, skills, and/or habits are transferred (including daycare, schooling/schools, university, continuing education, fieldwork placements, on-the-job learning, etc.)

Social Services-Social work, homeless shelters, battered women's services, disability support, etc. $26(14 \%)$

Government-Any relations connected to systems by which a State or community is governed (including legal, court, or prison systems; military; and municipal, provincial, or federal governance)

Community Organizing - A process where people who live or work in proximity to each other come together into an organization that acts in their shared self-interest

Immigration-Any relations addressing the immigration, settlement, or arrival of people

Humanitarian work-Aid and action designed to save lives, alleviate suffering, and maintain and protect human dignity during and in the aftermath of emergencies

Agriculture-Farming, food production, and the cultivation of animals, plants, and other life form for food, fiber, biofuel, and other products used to sustain and enhance human life

Other (including religious institutions, gender mainstreaming, anti-oppressive practices, North American cowboy culture, the discourse of black mothers, research relations, internationa development, housing and home ownership)

N/A-Did not investigate institutional relations (e.g., educative resource or conceptual paper) 
Because we chose to identify the most prominent or focal set of institutional relations central to the research or writing, which required distilling information into a single category or term, the richness and complexity of these relations is oversimplified.

\section{Discussion}

Our findings reveal the expansive scope of IE across disciplines, sectors, and countries including the breadth of ways it is being conceptualized and applied in practice. IE is diversely conceptualized as: a (sociological) method of inquiry, methodology, research approach, feminist sociology, theory and methodology, framework, lens, field, perspective, and form of analysis. Inevitably, authors applied IE differently across their research and writing, ranging from direct usage or close adherence to IE in a comprehensive manner; to indirect usage or loose adherence to IE by drawing on it as inspiration, guidance, or influence; or borrowing from a certain facet of IE such as a particular theory, concept, method, tool, or analytic strategy. Additionally, some authors adapted IE to suit a specific purpose, which entailed using modified versions of IE to fit a given context or objective; while others strived to extend existing understandings of IE through critique, explanation, review, elaboration, or reflection.

Importantly, when used as a method of inquiry, IE supported authors to: explicate the social organization of knowledge; depict textually-mediated relations; highlight contradictions between authoritative knowledge and practical knowledge and experience; make the often invisible work of particular people visible to others; show how ruling relations, discourses, and forms of institutional power organize and regulate people's lives; map out particular work processes; demonstrate how people's work in certain spheres of contemporary society is changing or being reorganized; question taken-for granted assumptions, practices, or knowledge; and provide an alternative analysis that shows or tells something new or different from previous work.

A key finding from our review is the significant extent to which IE is being used in combination with other theories, methodologies, or analytic tools. This issue reflects what appears to be a growing debate within the IE community-whether IE is amenable to being used in concert with other approaches. In fact, one of our expert consultants indicated that our Table 3 "opens up a can of worms" (Expert Consultation, October 5, 2015). At the core of this debate is IE's unique ontological position that continues to generate points of tension and ambiguity (Smith 2006; Walby 2007; 2013). Practitioners of IE are required to make the "ontological shift," which refers to a move from the "generalized world of conceptual and theoretical explanations" (Smith 2006:51) to the material world of people's everyday activities (Smith 2005). This distinction in IE is evident in every facet of its methodology, beginning with its rejection of theoretical supremacy, and the particular ways that methods are executed and data are analyzed. With such strong claims to a particular way of seeing the social world, and the directives around how its methods and analyses are carried out, the question of how other theories, methodologies, and methods can work in tandem with IE is tantamount to asking whether we can mix ontologies/epistemologies, which some researchers liken to a kind of "ontological gerrymandering" (Giacomini 2010). Yet, as Guba and Lincoln (2005:206) note, the paradigmatic controversies are mostly occurring at the borders, "the places that show the most promise for projecting where qualitative methods will be in the near and far future."

The tensions inherent in mixing ontological and epistemological differences are familiar in the burgeoning mixed methods/mixed research ${ }^{1}$ debates (Onwuegbuzie, Johnson, and Collins 2009; Hess-Biber and Johnson 2013; Morse and Cheek 2014; Howes 2015), which can inform how we think about "mixing" IE with other approaches and methodologies. At the core of the mixed research debate is whether methods, purposes, kinds of data, and levels of analysis from differing philosophical perspectives or paradigmatic stances can communicate with each other and be mixed or co-exist (Hess-Biber and Johnson 2013; Howes 2015). In response to this issue, proponents of mixed research have increasingly situated their projects within the construct of metaparadigms such as pragmatism and dialectical pluralism (Howes 2015). Similarly, Quinlan and Quinlan (2010) locate their pairing of IE and Social Network Analysis (SNA) within the pragmatist paradigm, using Habermas' theory of communicative action. While some of the authors in our review positioned their blending of IE with other methodologies/methods as a "mixed methods" design, few provided details or explications about the basis for their decisions, including, most importantly, the

"The term "mixed research," as opposed to "mixed methods research," indicates that mixing can occur at levels outside stances, data collection, and analysis (Howes 2015). philosophical underpinnings. This lack of methodological and philosophical clarity is at the forefront of the critique that mixed methods research has not, in the past, been sufficiently justified (Howes 2015), and continues to pose a significant barrier to rationalizing the mixing of IE with other approaches/ methods, as our review demonstrates. Explicating the reasons behind choosing to use IE as a "mixed design" can contribute to the development of institutional ethnographic research in innovative and promising ways.

The potential to cultivate relevant and effective methodological practices and designs that can answer research questions more completely is recognized in mixed research as occurring precisely in those spaces created by the "turbulence" of crisscrossing paradigms (Guba and Lincoln 2005; Hess-Biber and Johnson 2013; Howes 2015). Similarly, in our study, the intent to address complex political, educational, health, and other social research questions that could not be answered with IE alone was explicitly and implicitly the over-riding rationale authors gave in this category. They spoke of needing to "push methodological boundaries" (Taber 2010:6) and "contribute to the development of an innovative methodological approach" (Satka and Skehill 2011:192). Although the rationales provided were mostly convincing to us, we questioned what the implications might be if we are to take Dorothy Smith's (2005) stance that IE is not a methodology, but rather a "sociology." This is an important question to consider as Dorothy Smith's raison d'être for developing IE stems from her intent to provide an "alternate sociology" moving from an approach where people are typically considered as the objects 
of inquiry to an approach where aspects of the institutions relevant to people's experiences are the focus of inquiry (Smith 2005). Dorothy Smith (2005:2) cautions that although she has described IE as a "method of inquiry," it is in fact "a bit misleading" because "it is not just a methodology." Based on our review, it is evident that in its combination with other methodologies/approaches, IE is frequently being taken up as a methodology and as a method. The extent to which it is used as a methodology/method is particularly apparent in how authors described their rationale for combining IE with the work of other major theorists such as Foucault, Arendt, and Bourdieu (Mykhalovskiy et al. 2004; Nichols 2009; Gerrard and Farrell 2013). Authors highlight the "methodological" and "pragmatic tools" that IE offers, implying in some cases, that with its materialist grounding, IE can deliver the empirical instructions where other theorists and ideas cannot. The tension accompanying this rationale is evident throughout Nichols' (2009:63) paper, which she positions as "the outcome of my work to reconcile a loyalty to theory with a desire to use IE as an activist (and materialist) qualitative research strategy." Nichols (2009:72) reports on how she draws from Hannah Arendt's political theory, "easily anathema to IE" to provide the conceptual basis of the project, while moving forward with Dorothy Smith's standpoint concept that offers the "concrete place from which to investigate the social world" (Nichols 2009:64). In other projects where IE intersects with a Bourdieuian framework, IE is positioned as bringing "methodological clarity" (Gerrard and Farrell 2013); whereas within a Foucauldian perspective, the methodological approach "is shaped by Dorothy Smith's notion of institutional ethnography" (Butterwick and Daw- son 2005) and contributes an "empirical sociology of 'ruling relations'”' (Mykhalovskiy et al. 2004).

The question remains, if IE is being taken up as methodology, is the research project truly an "institutional ethnography" as outlined by its founder, Dorothy Smith, and does it matter? It matters in IE's call to work with other institutional ethnographers who in sharing the same ontology can bring together their separate studies of different institutional complexes. By illuminating the meta-discourses that cross organizations, institutions, and societies, deeper and far-reaching changes may be effected (DeVault 2006). Despite the potential merit of such a synthesis of institutional ethnographies, we did not come across any examples of this kind of work in our review. If we consider the impetus behind Dorothy Smith's creation of a "sociology for the people"-to help individuals understand how they are oppressed-the resolve as to whether IE can be taken up as a methodology leans in the affirmative direction. Institutional ethnography is a highly technical and complex practice demanding a kind of scholarly attention that requires sufficient research time to implement and translate in ways that are useful to changing people's lives. This challenge, identified as a constant and real struggle for institutional ethnographers (Campbell and Gregor 2002), is being addressed by the myriad ways that authors applied a specific aspect of IE to uncover the actualities of people's work, and relied on "practical" and "recognized" sources to help them analyze institutional ethnographic data (Expert Consultation, July 25, 2014), with varying needs, goals, contexts, resources, and expectations in mind. This actuality suggests IE's usefulness as a methodology across disciplines, at least for the scholars and researchers who continue to take it up in innovative ways.

\section{Limitations and Recommendations}

The challenges of conducting an IE scoping review are reflected in the limitations and subsequent recommendations we have outlined below. Given that IE is currently not a formal subject heading or an indexed term across databases, we were restricted to conducting a textword-specific search, which presented many difficulties. For example, using the textwords "institutional ethnograph" captured a number of irrelevant sources, including ones that (a) used "institutional" and "ethnography" in the same sentence, but not in reference to IE as a method of inquiry, (b) contained "institutional ethnography" in the title of one of their references, (c) cited an IE study, but did not actually employ Dorothy Smith's IE as part of their own approach, or (d) used the phrase "institutional ethnography" in reference to conducting an ethnography of or within an institution, which is not synonymous with employing IE as a method of inquiry. Consideration should be given to making IE a formal subject heading or indexed term across databases in order to support the further tracking, cataloguing, and study of this important body of work.

Categorizing and coding content from IE papers proved difficult, as the purpose and intent of IE is to resist categorization and classification. Our attempts to distil complex content into simple categories resulted in a loss of the richness and complexity that IE emphasizes. Additionally, restricting the scope of this study brought about several limitations. First, the timeframe of the data search did not capture all relevant works, such as the many formative studies seminal to the development of IE prior to 2003. Second, our decision to focus this scoping review strictly on peer-reviewed journal articles limited the breadth of information that could be gathered. During the investigation, we noted numerous book chapters, dissertations, conference abstracts, and front/back matter that directly addressed the utilization and application of institutional ethnography. Our review presents a very specific and detailed overview of trends and developments from the peer-reviewed journal article publications only, and omits summarizing the rich content from various types of IE works published elsewhere. Third, because of time constraints, we opted not to re-run the search after charting the sources, a practice that occurs in a small percentage of scoping reviews (Pham et al. 2014). As such, one of the significant limitations of this project is that the most recent manuscripts published after October 28, 2013 were omitted from our review. Fourth, a number of articles were excluded from this study because they were not available in English. Other languages in which these works were published included (but were not limited to): French, German, Italian, Portuguese, and Spanish. Collaborative international projects aimed at translating IE research across multiple languages are urgently required in order to build a shared understanding of how IE is being taken up around the globe.

Although some authors appeared to draw on an IE-informed analysis and cite works by Dorothy Smith, they did not explicitly use the terminology "institutional ethnography" to label or position 
their work, and consequently these sources were excluded from our study. In an effort to maintain a transparent research process and clear inclusion criteria, we refrained from reading between the lines to determine whether authors utilized institutional ethnography. Thus, the number of peer-reviewed IE journal publications may be higher than what we have captured. To ensure that IE work is included in future reviews which can advance the field, it is important that authors label their research and writing as institutional ethnography.

Additional omitted sources (a) described their work as conceptually, theoretically, methodologically, or analytically rooted in IE; and (b) referenced other institutional ethnographers; but did not (c) cite Dorothy Smith's work directly. One of our Expert Consultants suggested that "as a field matures the method rather than its founder is identified" (October 5,2015$)$. Learning about the origins and history of IE as developed by Dorothy Smith is essential to understanding IE's key tenets, ontology, orienting concepts, and associated commitments and politics. Whether taken up on its own or with other approaches and methodologies, IE is best and appropriately utilized when it is sufficiently understood. Citing Smith in a project that entails using IE, indicates a continued acknowledgement and commitment to the core principles of IE.

While Step 6 of Arksey and O'Malley's (2005) framework (involving the optional consultation with stakeholders in the field) was extremely beneficial, we felt that it came rather late in the course of our research process. Some of the consultants' requests were addressable, such as the provision of further clarifications, contextual details, and rationales; elaborations associated with IE terminology, our process, and the tensions we encountered; and an articulation of the main "take away" messages. However, other important comments and queries (such as attending to points of particular interest to seasoned institutional ethnographers, relevant historical details, and key concerns in the field) were difficult to tackle, since our data collection had already occurred. We suggest the inclusion of an additional optional stakeholder consultation prior to Arksey and O'Malley's (2005) fourth step of charting the data so that researchers can receive preliminary feedback in regards to: their research question, inclusion and exclusion criteria, operational definitions, and proposed chart headings. Such a consultation would enable teams to ensure they collect the appropriate data required to address key issues, and to make necessary adjustments to strengthen their research process and the utility of their findings.

Although it is beyond the scope of this review specifically, and of scoping reviews more generally, which traditionally refrain from judging the quality, appropriateness, or rigor of the research and writing of selected articles (Arksey and O'Malley 2005; Levac et al. 2010), there were instances when we engaged in informal debate with each other regarding the (in)compatibility of particular approaches that had been paired. The limited information, lack of explanation, and ambiguous rationales for combining IE with other methodologies/methods is a weakness we identified in numerous articles. We urge authors to clearly explicate how and to what degree they are drawing on IE and other theoretical, conceptual, methodological, or analytical tools in their research and writing (e.g., as primary approaches, secondary approaches, equivalent approaches, etc.). Rationales for, and the processes of, utilizing multiple approaches should be provided upfront with attention to opportunities and tensions. In addition to making an argument (or claim) for why the merging of specific tools is acceptable and worthwhile, offering an open discussion of the difficulties, dilemmas, and divergences encountered would prove helpful. We also suggest that experienced institutional ethnographers work together to create a concise but comprehensive resource that addresses (a) necessary features of institutional ethnographies, (b) common errors made in IE research and writing, and (c) the appropriateness of employing a range of tools in conjunction with IE.

\section{Future Research}

Considering the limits of what our project can answer, we propose numerous avenues for further investigation. For example, examining IE as a method of inquiry across the comprehensive body of grey literature (conference presentations, reports, magazines, newsletters, dissertations, etc.) and published literature (books, edited book chapters, handbooks, encyclopedia entries, etc.) will contribute to a deeper and expanded understanding of how IE is taken up as a method of inquiry. Future scoping studies should also document (a) the IE-specific analysis steps that were employed; (b) whether or not the project was funded (and if so, the funding source); (c) authors' professional positions (graduate student, professor, community activist, etc.) and disciplinary affiliations; and (d) type of IE (e.g., predominantly textual, discursive/ideological, change-oriented, historical, and so on). Such documentation will provide important information about the IE analysis process, the funding bodies or sources that support IE research, the people who employ IE, and the range of IE works that exist.

Moreover, we recommend that prospective reviews trace the historical evolution of IE. Mapping Dorothy Smith's connection to authors by decade, based on (a) a direct relationship (such as colleague, advisor, committee member, external examiner, instructor, etc.); (b) an indirect relationship (for instance, one of Dorothy Smith's former advisees is now an advisor or committee member to the author); or (c) no known relationship, might enable the identification of authors as first-, second-, third-, fourth-, fifth-, or new-generation IE users. Data could be examined for patterns based on how different generations of Institutional Ethnographers have referred to, utilized, and taken up IE over time. Such a study might offer a novel picture of the IE community, the proliferation of IE, and the future of IE. Indeed, questions remain as to whether certain orienting concepts and tenets have become muddled or misused over the years, and whether there is an immediate need to clarify and preserve the shared language that cuts across disciplinary divides, so that it remains intact and well-understood long after Dorothy Smith and first-generation institutional ethnographers have stopped teaching, researching, and mentoring new scholars in the field.

Examining ruling relations based on public and private sector groupings in order to uncover noteworthy distinctions, interrelationships, and changes (as was suggested by one of our Expert Consultants) 
fell beyond the scope of this project; however, it is another important area for future inquiry. Finally, exploring the uptake of IE in particular areas identified in our review, such as healthcare and education, could reveal important key trends and patterns of ruling relations.

\section{Conclusion}

The strength of IE as it is variously taken up as a method of inquiry is evident in the range of scholars, researchers, professionals, and activists engaging with IE across a myriad of disciplines, countries, and sectors. The question of whether it is appropriate to use IE with other theories, methodologies, methods, and analytic tools continues to be of growing interest and warrants ongoing discussion. Regardless of the answer, it is clear from our review that authors are applying IE to their research and writing projects

\section{References}

Adams, Jill. 2009. “The Civil Restraining Order Application Process." Ethnography 10(2):185-211.

Aldinger, Carmen et al. 2008. "Strategies for Implementing Health-Promoting Schools in a Province in China." Promotion \& Education 15(1):24-29.

Arksey, Hilary and Lisa J. O'Malley. 2005. “Scoping Studies: Towards a Methodological Framework." International Journal of Social Research Methodology 8(1):19-32.

Bain, Beverly. 2010. “Uncovering Conceptual Practices: Bringing into 'Lived Consciousness' Feminists' Activities on the Toronto Police Sexual Assault Audit and the Follow-Up Sexual in both conventional and unexpected ways. We urge the IE community, in all its forms, to fully know and explicate IE, however they choose to take it up.

\section{Acknowledgements}

We acknowledge the invaluable assistance of Elizabeth Uleryk, from the Hospital Library and Archives, at the Hospital for Sick Children in Toronto, Canada. Elizabeth was instrumental in providing guidance throughout our formal literature review process. We also thank Laurie Clune for the candid and practical advice she provided as part of a midpoint consultation. Finally, we extend sincere gratitude to our Stage 6 consultation experts: Jan Angus, Janet Rankin, Dorothy Smith, and Suzanne Vaughan. Their contributions enhanced our findings, informed our revisions, and added methodological rigor to our process.

Assault Audit Steering Committee." Canadian Woman Studies 28(1):15-21.

Baines, Donna. 2010. "Gender Mainstreaming in a Development Project: Intersectionality in a Post-Colonial Un-Doing?" Gender, Work \& Organization 17(2):119-149.

Barry, Janice and Libby Porter. 2012. “Indigenous Recognition in State-Based Planning Systems: Understanding Textual Mediation in the Contact Zone." Planning Theory 11(2):170-187.

Beck, Kumari et al. 2013. “New Work, Old Power: Inequities within the Labor of Internationalization." On the Horizon 21(2):84-95.
Bell, Nancy M. and Marie L. Campbell. 2003. “A Child's Death: Lessons from Health Care Providers' Texts." Journal of Sociology \& Social Welfare 30(1):113-126.

Berkowitz, Dana and William Marsiglio. 2007. “Gay Men: Negotiating Procreative, Father, and Family Identities." Journal of Marriage \& Family 69(2):366-381.

Berkowitz, Dana, Linda Belgrave, and Robert A. Halberstein. 2007. "The Interaction of Drag Queens and Gay Men in Public and Private Spaces." Journal of Homosexuality 52(3-4):11-32.

Bisaillon, Laura. 2011. “Mandatory HIV Screening Policy and Everyday Life: A Look Inside the Canadian Immigration Medical Examination." Aporia: The Nursing Journal 3(4):5-14.

Bisaillon, Laura. 2012. “An Analytic Glossary to Social Inquiry Using Institutional and Political Activist Ethnography." International Journal of Qualitative Methods 11(5):607-627.

Bisaillon, Laura. 2013. "Contradictions and Dilemmas within the Practice of Immigration Medicine." Canadian Journal of Public Health 104(1):e45-e51.

Bisaillon, Laura and Janet Rankin. 2013. “Navigating the Politics of Fieldwork Using Institutional Ethnography: Strategies for Practice." Forum: Qualitative Social Research 14(1). Retrieved August 14, 2013 (http://nbn-resolving.de/urn:nbn:de:0114-fqs1301144).

Braaf, Sandra, Elizabeth Manias, and Robin Riley. 2013. “The 'Time-Out' Procedure: An Institutional Ethnography of How It Is Conducted in Actual Clinical Practice." BMJ Quality \& Safety 22(8):647-655.

Breitkreuz, Rhonda S. and Deanna L. Williamson. 2012. “The Self-Sufficiency Trap: A Critical Examination of Welfare-toWork." Social Service Review 86(4):660-689.

Breitkreuz, Rhonda S., Deanna L. Williamson, and Kim D. Raine. 2010. "Dis-Integrated Policy: Welfare-to-Work Participants' Experiences of Integrating Paid Work and Unpaid Family Work." Community, Work \& Family 13(1):43-69.

Brotman, Shari. 2003. “The Limits of Multiculturalism in Elder Care Services." Journal of Aging Studies 17(2):209-229.
Brown, Debra J. 2006. “Working the System: Re-Thinking the Institutionally Organized Role of Mothers and the Reduction of 'Risk' in Child Protection Work." Social Problems 53(3): 352-370.

Bruch, Elizabeth M. 2013. "Having the Last Word: Human Rights Reporting (Re)Imagined through Critical Qualitative Methodology." Qualitative Sociology 36(2):209-225.

Butterwick, Shauna and Jane Dawson. 2005. “Undone Business: Examining the Production of Academic Labour." Women's Studies International Forum 28(1):51-65.

Campbell, Marie. 2003. “Dorothy Smith and Knowing the World We Live In." Journal of Sociology and Social Welfare 30(1):3-22.

Campbell, Marie and Frances Gregor. 2002. Mapping Social Relations: A Primer in Doing Institutional Ethnography. Ontario: Garamond Press.

Campbell, Marie and Elena Kim. 2011. “Working Across Boundaries: Exploring the Relations of Researching Gender and Development." Women \& Therapy 34(3):261-278

Campbell, Marie L. and Katherine Teghtsoonian. 2010. “Aid Effectiveness and Women's Empowerment: Practices of Governance in the Funding of International Development." Signs 36(1):177-202.

Carrier, Annie and Birgit Prodinger. 2014. “Visions of Possibility: Using Institutional Ethnography as a Theory and Method for Understanding Contexts and Their Ruling Relations." Occupational Therapy Now 16(2):18-21.

Cleeton, Elaine R. 2003. “'Are You Beginning to See a Pattern Here?' Family and Medical Discourses Shape the Story of Black Infant Mortality." Journal of Sociology and Social Welfare 30(1):41-63.

Comber, Barbara. 2012. “Mandated Literacy Assessment and the Reorganisation of Teachers' Work: Federal Policy, Local Effects." Critical Studies in Education 53(2):119-136.

Comber, Barbara and Phil Cormack. 2011. “Education Policy Mediation: Principals' Work with Mandated Literacy Assessment." English in Australia 46(2):77-86. 
Comber, Barbara and Helen Nixon. 2009. “Teachers' Work and Pedagogy in an Era of Accountability." Discourse: Studies in the Cultural Politics of Education 30(3):333-345.

Cormack, Phillip and Barbara Comber. 2013. “High-Stakes Literacy Tests and Local Effects in a Rural School." The Australian Journal of Language and Literacy 36(2):78-89.

Creswell, John W. 2005. Educational Research: Planning, Conducting, and Evaluating Quantitative and Qualitative Research. 2nd Edition. Upper Saddle River, NJ: Pearson Education.

Creswell, John W. 2007. Qualitative Inquiry and Research Design: Choosing among Five Approaches. 2nd Edition. Thousand Oaks: Sage.

Dale, Craig et al. 2013. “Mouth Care for Orally Intubated Patients: A Critical Ethnographic Review of the Nursing Literature." Intensive \& Critical Care Nursing 29(5):266-274.

Daniel, Yvette. 2005. “The Textual Construction of High Needs for Funding Special Education in Ontario." Canadian Journal of Education 28(4):763-783.

Daudt, Helena M. L., Catherine van Mossel, and Samantha J. Scott. 2013. "Enhancing the Scoping Study Methodology: A Large, Inter-Professional Team's Experience with Arksey and O'Malley's Framework." BMC Medical Research Methodology 13(48). Retrieved July 23, 2013 (http://www.biomedcentral. com/1471-2288/13/48).

David, Miriam E. 2008. “Social Inequalities, Gender and Lifelong Learning." The International Journal of Sociology and Social Policy 28(7/8):260-272.

de Montigny, Gerald. 2003. “Textual Regulation of Child Welfare: A Critique of the Ontario Risk Assessment Model." Canadian Review of Social Policy 52:33-50.

de Montigny, Gerald. 2011. “Beyond Anti-Oppressive Practice: Investigating Reflexive Social Relations." Journal of Progressive Human Services 22(1):8-30

Denzin, Norman K. and Yvonna S. Lincoln, (eds.). 2005. The Sage Handbook of Qualitative Research. 3rd Edition. Thousand Oaks: Sage.
Dergousoff, Debbie. 2008. “Ethnobotany, Institutional Ethnography, and the Knowledge of Ruling Relations." Canadian Journal of Native Education 31(1):162-178.

DeVault, Marjorie L. 2006. “Introduction: What Is Institutional Ethnography?" Social Problems 53(3):294-298.

DeVault, Marjorie L. and Lisa McCoy. 2006. "Institutional Ethnography: Using Interviews to Investigate Ruling Relations." Pp. 15-44 in Institutional Ethnography as Practice, edited by Dorothy E. Smith. Lanham: Rowman \& Littlefield.

Deveau, Jean Louis. 2008. “Examining the Institutional Ethnographer's Toolkit." Socialist Studies 4(2):1-19.

Deveau, Jean Louis. 2011. “Workplace Accommodation and Audit-Based Evaluation Process for Compliance with the Employment Equity Act: Inclusionary Practices That Exclude-An Institutional Ethnography." Canadian Journal of Sociology 36(3):151-172

Dyjur, Louise, Janet Rankin, and Annette Lane. 2011. "Math for Medications: An Analytical Exemplar of the Social Organization of Nurses' Knowledge." Nursing Philosophy 12(3):200-213.

Eells, Jean Crim. 2010. “Loving the Land Is Not Enough: Empowering Women Landowners to Prevent Environmental Degradation." Ecopsychology 2(3):179-185.

Eveline, Joan, Carol Bacchi, and Jennifer Binns. 2009. "Gende Mainstreaming Versus Diversity Mainstreaming: Methodology as Emancipatory Politics." Gender, Work and Organization 16(2):198-216.

Fisher, Jill A. 2006a. “Procedural Misconceptions and Informed Consent: Insights from Empirical Research on the Clinical Trials Industry." Kennedy Institute of Ethics Journal 16(3):251-268.

Fisher, Jill A. 2006b. "Co-Ordinating 'Ethical' Clinical Trials The Role of Research Coordinators in the Contract Research Industry." Sociology of Health \& Illness 28(6):678-694.

Fisher, Jill A. 2010. "Re-Inscribing Gender in New Modes of Medical Expertise: The Investigator-Coordinator Relationship in the Clinical Trials Industry." Gender, Work \& Organization 17(2):150-173.
Folkmann, Louise and Janet Rankin. 2010. “Nurses' Medication Work: What Do Nurses Know?" Journal of Clinical Nursing 19(21/22):3218-3226.

Gerrard, Jessica and Lesley Farrell. 2013. “'Peopling' Curriculum Policy Production: Researching Educational Governance through Institutional Ethnography and Bourdieuian Field Analysis." Journal of Education Policy 28(1):-1-20.

Giacomini, Mita. 2010. "Theory Matters in Qualitative Research." Pp. 125-156 in The Sage Handbook of Qualitative Methods in Health Research, edited by I. Bourgeault, R. Dingwall, R. de Vries. London: Sage.

Gibson, Kerri, Susan O’Donnell, and Vanda Rideout. 2007. “The Project-Funding Regime: Complications for Community Organizations and Their Staff." Canadian Public Administration 50(3):411-436.

Godderis, Rebecca. 2011. "From Talk to Action: Mapping the Diagnostic Process in Psychiatry." Advances in Medical Sociology 12:133-152.

Gómez, Maria and Marjo Kuronen. 2011. “Comparing Local Strategies and Practices: Recollections from Two Qualitative Cross-National Research Projects." Qualitative Research 11(6):683-697.

Good-Gingrich, Luann. 2003. "Constructing Identity and Drawing Lines: The Textual Work of Ontario's Safe Streets Act." Journal of Canadian Studies 37(4):151-170.

Goodman, Philip. 2008. “It's Just Black, White, or Hispanic?: An Observational Study of Racializing Moves in California's Segregated Prison Reception Centers." Law \& Society Review 42(4):735-770.

Grace, Daniel. 2003. "Transnational Institutional Ethnography: Tracing Text and Talk Beyond State Boundaries." International Journal of Qualitative Methods 12:587-605.

Grahame, Kamini Maraj. 2003. “For the Family': Asian Immigrant Women's Triple Day." Journal of Sociology and Social Welfare 30(1):65-90.

Grahame, Peter R. and Kamini Maraj Grahame. 2009. “Points of Departure: Insiders, Outsiders, and Social Relations in Caribbean Field Research." Human Studies 32(3):291-312.
Guba, Egon G. and Yvonna S. Lincoln. 2005. "Paradigmatic Controversies, Contradictions and Emerging Confluences." Pp. 191-215 in Handbook of Qualitative Research, $3^{\text {rd }}$ Edition, edited by N. K. Denzin, Y. S. Lincoln. Thousand Oaks: Sage.

Hamilton, Mary. 2009. “Putting Words in Their Mouths: The Alignment of Identities with System Goals through the Use of Individual Learning Plans." British Educational Research Journal 35(2):221-242.

Hamilton, Patti and Marie Campbell. 2011. "Knowledge for Re-Forming Nursing's Future: Standpoint Makes a Difference," Advances in Nursing Science 34(4):280-296.

Hamilton, Patti et al. 2010. “Expanding What We Know about Off-Peak Mortality in Hospitals." Journal of Nursing Administration 40(3):124-128.

Haneda, Mari and Jan Nespor. 2013. "Strangers and Professionals: Positioning Discourse in ESL Teachers' Work." The Urban Review 45(3):251-272.

Harrison, Deborah. 2006. “The Role of Military Culture in Military Organizations' Responses to Woman Abuse in Military Families." The Sociological Review 54(3):546-574.

Harrison, Elisabeth. 2012. "The Body Economic: The Case of “Childhood Obesity."' General Feminism \& Psychology 22(3):324-343.

Hart, Randle J. and Andrew McKinnon. 2010. “Sociological Epistemology: Durkheim's Paradox and Dorothy E. Smith's Actuality." Sociology 44(6):1038-1054

Hess-Biber, S. and R. Burke Johnson. 2013. “Coming at Things Differently: Future Directions of Possible Engagement with Mixed Methods Research." Journal of Mixed Methods Research 7(2):103-109.

Hicks, Stephen. 2009. "Sexuality and the 'Relations of Ruling' Using Institutional Ethnography to Research Lesbian and Gay Foster Care and Adoption." Social Work \& Society 7(2):234-245.

Høgsbro, Kjeld. 2010. “Simreb-Towards a Systematic Inquiry into Models for Rehabilitation." Scandinavian Journal of Disability Research 12(1):1-18. 
Howes, Leone M. 2015. “Developing the Methodology for an Applied, Interdisciplinary Research Project: Documenting the Journey Toward Philosophical Clarity." Journal of Mixed Methods Research. Retried December 15, 2015 (http://mmr.sagepub. com/content/early/2015/12/16/1558689815622018.abstractN2).

Hussey, Ian. 2012. “'Political Activist as Ethnographer,' Revisited." Canadian Journal of Sociology 37(1):1-24.

Husso, Marita and Helena Hirvonen. 2012. “Gendered Agency and Emotions in the Field of Care Work." Gender, Work \& Organization 19(1):29-51.

Jakubec, Sonia L. and Marie Campbell. 2003. "Mental Health Research and Cultural Dominance: The Social Construction of Knowledge for International Development." Canadian Journal of Nursing Research 35(2):75-88.

Janik-Marusov, Laura L. et al. 2011. "From Tactics to Praxis: Learning Feminist Pedagogy Through Methodology." Qualitative Report 16(6):1517-1539.

Jung, Karen E. 2003. “Chronic Illness and Academic Accommodation: Meeting Disabled Students' 'Unique Needs' and Preserving the Institutional Order of the University." Journal of Sociology \& Social Welfare 30:91-112.

Kennedy, Holly P. et al. 2010. “Normalizing Birth in England: A Qualitative Study." Journal of Midwifery \& Women's Health 55(3):262-269.

King, Brian. 2009. "Commercializing Conservation in South Africa." Environment \& Planning 41(2):407-424.

Klaver, Klaartje and Andries Baart. 2011. "Attentiveness in Care: Towards a Theoretical Framework." Nursing Ethics 18(5):686-693.

Knaak, Stephanie. 2005. "Breast-Feeding, Bottle-Feeding and Dr. Spock: The Shifting Context of Choice." The Canadian Review of Sociology and Anthropology 42(2):197-216.

Krusen, Nancy. 2011. "The Influence of Environment on Clinical Practice: Unspoken Rules." British Journal of Occupational Therapy 74(12):546-553.
Kushner, Kaysi E. 2005. “Embodied Context: Social Institutional Influences on Employed Mothers' Health." Health Care for Women International 26(1):69-86.

Kushner, Margot Ann. 2006a. "Is ‘Best Interests' a Solution to Filling Potholes in Child Custody Planning?" Journal of Child Custody 3(2):71-90.

Kushner, Margot Ann. 2006b. “Whose Best Interests: The Ruling or the Children?" General Journal of Divorce \& Remarriage 44(3-4):17-29.

LaFrance, Michelle and Melissa Nicolas. 2012. "Institutional Ethnography as Materialist Framework for Writing Program Research and the Faculty-Staff Work Standpoints Project." College Composition and Communication 64(1):130-150

Lane, Annette M. 2011. “Placement of Older Adults from Hospital Mental Health Units into Nursing Homes: Exploration o the Process, System Issues, and Implications." Journal of Gerontological Nursing 37(2):49-55.

Lane, Annette, Liza McCoy, and Carol Ewashen. 2010. "The Textual Organization of Placement into Long-Term Care: Issues for Older Adults with Mental Illness." Nursing Inquiry 17(1):2-13.

Leonard, Lori and Jonathan M. Ellen. 2008. “'The Story of My Life': Aids and 'Autobiographical Occasions."' Qualitative Sociology 31(1):37-56

Levac, Danielle, Heather Colquhoun, and Kelly K. O'Brien. 2010. "Scoping Studies: Advancing the Methodology." Imple mentation Science 5(69). Retrieved July 23, 2013 (http://www.implementationscience.com/content/5/1/69).

Limoges, Jacques. 2010. "An Exploration of Ruling Relation and How They Organize and Regulate Nursing Education in the High-Fidelity Patient Simulation Laboratory." Nursing Inquiry 17(1):57-63.

Lowndes, Ruth, Jan Angus, and Elizabeth Peter. 2013. “Diabetes Care and Mental IIlness: Constraining Elements to Physical Activity and Social Participation in a Residential Care Facility." Canadian Journal of Diabetes 37(4):220-225.
Luken, Paul C. and Suzanne Vaughan. 2003a. “'Active Living': Transforming the Organization of Retirement and Housing in the U.S." Journal of Sociology and Social Welfare 30(1):145-169.

Luken, Paul C. and Suzanne Vaughan. 2003b. “Living Alone in Old Age: Institutionalized Discourse and Women's Knowledge." Sociological Quarterly 44(1):109-131.

Luken, Paul C. and Suzanne Vaughan. 2005. “Be a Genuine Homemaker in Your Own Home': Gender and Familial Relations in State Housing Practices, 1917-1922." Social Forces 83(4):1603-1626.

Luken, Paul C. and Suzanne Vaughan. 2006. "Standardizing Childrearing through Housing." Social Problems 53(3):299-331.

Lund, Rebecca. 2012. “Publishing to Become an 'Ideal Academic': An Institutional Ethnography and a Feminist Critique." Scandinavian Journal of Management 28(3):218-228.

Lynam, Judith M. 2005. “Health as a Socially Mediated Process: Theoretical and Practice Imperatives Emerging from Research on Health Inequalities." Advances in Nursing Science 28(1):25-37.

MacKinnon, Karen. 2006. “Living with the Threat of Preterm Labor: Women's Work of Keeping the Baby In." Journal of Obstetric, Gynecologic \& Neonatal Nursing 35(6):700-708.

MacKinnon, Karen A. 2008. “Labouring to Nurse: The Work of Rural Nurses Who Provide Maternity Care." Rural \& Remote Health 8(4):10-47.

MacKinnon, Karen. 2010. “Learning Maternity: Rural Nurses Experiences." Canadian Journal of Nursing Research 42(1):38-55.

MacKinnon, Karen. 2011. “Rural Nurses' Safeguarding Work: Reembodying Patient Safety." Advances in Nursing Science 34(2):119-129.

MacKinnon, Karen. 2012. “We Cannot Staff for 'What Ifs': The Social Organization of Rural Nurses' Safeguarding Work." Nursing Inquiry 19(3):259-269.

MacKinnon, Karen and Marjorie McIntyre. 2006. “From Braxton Hicks to Preterm Labour: The Constitution of Risk in Pregnancy." Canadian Journal of Nursing Research 38(2):56-72.
Maher, Frances A. and Mary Kay Thompson Tetreault. 2011. "Long-Term Transformations: Excavating Privilege and Diversity in the Academy." Gender and Education 23(3):281-297.

Malinsky, Lynn, Ruth DuBois, and Diane Jacquest. 2010 "Building Scholarship Capacity and Transforming Nurse Educators' Practice through Institutional Ethnography." International Journal of Nursing Education Scholarship 7(1): $1-12$.

Marshall, June et al. 2012. "Balancing Interests of Hospitals and Nurse Researchers: Lessons Learned." Applied Nursing Research 25(3):205-211.

McCoy, Liza. 2005. "HIV-Positive Patients and the Doctor-Patient Relationship: Perspectives from the Margins." Qualitative Health Research 15(6):791-806.

McCoy, Liza and Cristi Masuch. 2007. "Beyond 'Entry-Level' Jobs: Immigrant Women and Non-Regulated Professiona Occupations." Journal of International Migration and Integration 8(2):185-206

McGibbon, Elizabeth and Elizabeth Peter. 2008. "An Ethnography of Everyday Caring for the Living, the Dying, and the Dead: Toward a Biomedical Technography." Qualitative Inquiry 14(7):1134-1156.

McGibbon, Elizabeth, Elizabeth Peter, and Ruth Gallop. 2010. “An Institutional Ethnography of Nurses' Stress." Qualitative Health Research 20(10):1353-1378.

McNamara, Nora and Stephen Morse. 2004. "Voices from the Aid 'Chain': The Personal Dynamics of Care." Social \& Cultural Geography 5(2):253-270.

McNeil, Lori. 2005. “Understanding Childcare through Experiential Knowledge." Michigan Sociological Review 19:86-114.

McNeil, Lori L. 2008. "Applying Institutional Ethnography to Childcare." Qualitative Sociology Revieww 4(1):109-130.

Medves, Jennifer M. and Barbara L. Davies. 2005. “Sustaining Rural Maternity Care-Don't Forget the RNs." Canadian Journal of Rural Medicine 10(1):29-35. 
Melon, Karen A., Deborah White, and Janet Rankin. 2013. “Beat the Clock! Wait Times and the Production of 'Quality' in Emergency Departments." Nursing Philosophy 14(3):223-237.

Moll, Sandra et al. 2013. “When Health Care Workers Experience Mental Ill Health: Institutional Practices of Silence." Qualitative Health Research 23(2):167-179.

Morse, Janice M. and Julianne Cheek. 2014. “Making Room for Qualitatively-Driven Mixed-Method Research." Qualitative Health Research 24(1):3-5.

Moser, Mary Anne. 2009. “Text 'Superpowers': A Study of Computers in Homeless Shelters." Science, Technology \& Human Values 34(6):705-740.

Mumtaz, Zubia et al. 2012. "Are Community Midwives Addressing the Inequities in Access to Skilled Birth Attendance in Punjab, Pakistan? Gender, Class and Social Exclusion." BMC Health Services Research 12:326. Retrieved July 06, $2014 \quad$ (http://bmchealthservres.biomedcentral.com/articles/10.1186/1472-6963-12-326).

Muñoz-Laboy, Miguel A. et al. 2011. "[Commentary on] Beyond Faith-Based Organizations: Using Comparative Institutional Ethnography to Understand Religious Responses to HIV and Aids in Brazil." American Journal of Public Health 101(6):972-978.

Murray, Karen Bridget, Jacqueline Low, and Angela Waite. 2006. "The Voluntary Sector and the Realignment of Government: A Street-Level Study." Canadian Public Administration 49(3):375-392

Murray, Kate M. 2012. “Regulating Activism: An Institutional Ethnography of Public Participation." Community Development Journal 47(2):199-215.

Murray, Laura R. et al. 2012. “Strange Bedfellows: The Catholic Church and Brazilian National Aids Program in the Response to HIV/Aids in Brazil." Social Science \& Medicine 72(6):945-952.

Mykhalovskiy, Eric. 2003. “Evidence-Based Medicine: Ambivalent Reading and the Clinical Recontextualization of Science." Health: An Interdisciplinary Journal for the Social Study of Health, Illness \& Medicine 7(3):331-352.
Mykhalovskiy, Eric. 2008. "Beyond Decision Making: Class, Community Organizations, and the Healthwork of People Living with HIV/AIDS. Contributions from Institutional Ethnographic Research." Medical Anthropology 27(2):136-163.

Mykhalovskiy, Eric and Liza McCoy. 2002. "Troubling Ruling Discourses of Health: Using Institutional Ethnography in Community-Based Research." Critical Public Health 12(1):17-37.

Mykhalovskiy, Eric, Liza McCoy, and Michael Bresalier. 2004 "Compliance/Adherence, HIV, and the Critique of Medical Power." Social Theory \& Health 2(4):315-340.

Nichols, Naomi. 2008a. "Understanding the Funding Game The Textual Coordination of Civil Sector Work." Canadian Journal of Sociology 33(1):61-87.

Nichols, Naomi. 2008b. "Gimme Shelter! Investigating the Social Service Interface from the Standpoint of Youth." Journal of Youth Studies 11(6):685-699.

Nichols, Naomi. 2009. “Strange Bedfellows: A Transformative Community-Based Research Project Inspired by Hannah Arendt and Dorothy E. Smith." Theory in Action 2(2):61-73.

Nichols, Naomi and Alison I. Griffith. 2009. “Talk, Texts, and Educational Action: An Institutional Ethnography of Policy in Practice." Cambridge Journal of Education 39(2):241-255.

Nilsson, Lina et al. 2012. “The Importance of Interaction in the Implementation of Information Technology in Health Care A Symbolic Interactionism Study on the Meaning of Accessibility." Informatics for Health \& Social Care 37(4):277-290.

Onwuegbuzie, Anthony J., Burk Johnson, and Kathleen Collins. 2009. "A Call for Mixed Analysis: A Philosophical Framework for Combining Qualitative and Quantitative." International Journal of Multiple Research Approaches 3:114-139.

O'Shaughnessy, Sarah and Naomi T. Krogman. 2012. “A Revolution Reconsidered? Examining the Practice of Qualitative Research in Feminist Scholarship." Signs 37(2):493-520.

Parada, Henry, Lisa Barnoff, and Brienne Coleman. 2007 “Negotiating 'Professional Agency': Social Work and Deci-
sion-Making within the Ontario Child Welfare System." Journal of Sociology and Social Welfare 34(4):35-56.

Paterson, Barbara L., Margaret Osborne, and David Gregory. 2004. "How Different Can You Be and Still Survive? Homogeneity and Difference in Clinical Nursing Education." International Journal of Nursing Education Scholarship 1(1): Art. 2.

Pence, Ellen and Martha McMahon. 2003. “Working from Inside and Outside Institutions: How Safety Audits Can Help Courts' Decision Making Around Domestic Violence and Child Maltreatment." Juvenile and Family Court Journal 54(4):133-148.

Perreault, Thomas. 2003. “Changing Places: Transnational Networks, Ethnic Politics, and Community Development in the Ecuadorian Amazon." Political Geography 22(1):61-88.

Pham, Mai T. et al. 2014. "A Scoping Review of Scoping Reviews: Advancing the Approach and Enhancing the Consistency." Research Synthesis Methods 5(4):371-385.

Pozzuto, Richard M., Margaret Arnd-Caddigan, and Paige Averett. 2009. “Notes in Support of a Relational Social Work Perspective: A Critical Review of the Relational Literature with Implications for Macro Practice." Smith College Studies in Social Work (Haworth) 79(1):5-16.

Prodinger, Birgit and Susan Marie Turner. 2013. “Using Institutional Ethnography to Explore How Social Policies Infiltrate into Daily Life." Journal of Occupational Science 20(4):357-369.

Prodinger, Birgit et al. 2012. "Arthritis-Related Occupational Therapy: Making Invisible Ruling Relations Visible Using Institutional Ethnography." British Journal of Occupational Therapy 75(10):463-470.

Quinlan, Elizabeth. 2008. "Conspicuous Invisibility: Shadowing as a Data Collection Strategy." Qualitative Inquiry 14(8):1480-1499.

Quinlan, Elizabeth. 2009. “The 'Actualities' of Knowledge Work: An Institutional Ethnography of Multi-Disciplinary Primary Health Care Teams." Sociology of Health \& Illness 31(5):625-641.
Quinlan, Elizabeth and Andrea Quinlan. 2010. “Representations of Rape: Transcending Methodological Divides." Journal of Mixed Methods Research 4(2):127-143.

Rankin, Janet. M. 2003. "Patient Satisfaction': Knowledge for Ruling Hospital Reform-An Institutional Ethnography." Nursing Inquiry 10(1):57-65.

Rankin, Janet M. 2009. "The Nurse Project: An Analysis fo Nurses to Take Back Our Work." Nursing Inquiry 16(4):275-286.

Rankin, Janet and Marie Campbell. 2009. "Institutional Ethnography (IE), Nursing Work and Hospital Reform: IE's Cautionary Analysis." Forum Qualitative Sozialforschung / Forum: Qualitative Social Research 10(2). Retrieved July 23, 2014 (http://www.qualitative-research.net/index.php/fqs/article/ view/1258/2720).

Rankin, Janet M. et al. 2010. “Contesting Our Taken-for-Granted Understanding of Student Evaluation: Insights from a Team of Institutional Ethnographers." Journal of Nursing Education 49(6):333-339.

Redvers, Jennifer et al. 2015. “A Scoping Review of Indigenous Suicide Prevention in Circumpolar Regions." International Journa of Circumpolar Health 74. Retrieved November 20, 2015 (http://www. circumpolarhealthjournal.net/index.php/ijch/article/view/27509).

Reimer, Marilee and Melanie Ste-Marie. 2010. “Denied Access The Focus on Medicalized Support Services and 'Depressed' Women Students in the Corporate University." Resources for Feminist Research 33(3-4):137-160.

Restoule, Jean-Paul et al. 2013. “Supporting Successful Transition to Post-Secondary Education for Indigenous Students: Lesson from an Institutional Ethnography in Ontario, Canada." International Indigenous Policy Journal 4(4). Retrieved July 11, 2014 (http:// search.proquest.com/docview/1629328806?accountid=14771)).

Ross, Tim. 2013. “Advancing Ontario's Accessibility: A Study of Linguistic, Discursive, and Conceptual Barriers." Canadian Journal of Urban Research 22(1):126-144

Rusted, Brian. 2006. “Performing Visual Discourse: Cowboy Art and Institutional Practice." Text and Performance Quarterly 26(2):115-137. 
Sadusky, Jane M. et al. 2010. “The Praxis Safety and Accountability Audit: Practicing a 'Sociology for People."' Violence Against Women 16(9):1031-1044.

Salazar, Egla Martinez. 2008. "State Terror and Violence as a Process of Lifelong Teaching-Learning: The Case of Guatemala." International Journal of Lifelong Education 27(2):201-216.

Salmon, Amy. 2007. “Adaptation and Decolonization: Unpacking the Role of 'Culturally Appropriate' Knowledge in the Prevention of Fetal Alcohol Syndrome." Canadian Journal of Native Education 30(2):257-274.

Satka, Mirja Eila and Caroline Skehill. 2011. “Michel Foucault and Dorothy Smith in Case File Research: Strange Bed-Fellows or Complementary Thinkers?" Qualitative Social Work 11(2):191-205.

Schwandt, Thomas A. 2007. The Sage Dictionary of Qualitative Inquiry. 3rd Edition. Los Angeles: Sage.

Scott, Catherine M. and Wilfreda E. Thurston. 2004. “The Influence of Social Context on Partnerships in Canadian Health Systems." Gender Work and Organization 11(5):481-505.

Shan, Hongxia. 2009. "Shaping the Re-Training and Re-Education Experiences of Immigrant Women: The Credential and Certificate Regime in Canada." International Journal of Lifelong Education 28(3):353-369.

Sinding, Christina. 2010. “Using Institutional Ethnography to Understand the Production of Health Care Disparities." Qualitative Health Research 20(12):1656-1663.

Sinding, Christina et al. 2012. "Of Time and Troubles: Patient Involvement and the Production of Health Care Disparities." Health: An Interdisciplinary Journal for the Social Study of Health, Illness \& Medicine 16(4):400-417.

Slade, Bonnie. 2012. “'From High Skill to High School': Illustrating the Process of Deskilling Immigrants through Reader's Theatre and Institutional Ethnography." Qualitative Inquiry 18(5):401-413.

Smith, Dorothy E. 1987. The Everyday World as Problematic: A Feminist Sociology. Toronto: University of Toronto Press.
Smith, Dorothy E. 1990. The Conceptual Practices of Power. A Feminist Sociology of Knowledge. Toronto: University of Toronto Press.

Smith, Dorothy E. 1996. “The Relations of Ruling: A Feminist Inquiry." Studies in Cultural Organization and Society 2:171-190.

Smith, Dorothy E. 2003. "Making Sense of What People Do: A Sociological Perspective." Journal of Occupational Science 10(1):61-64.

Smith, Dorothy E. 2005. Institutional Ethnography: A Sociology for People. Toronto: Rowman and Littlefield.

Smith, Dorothy E. 2007. “Making Change from Below.” Socialis Studies: The Journal of the Society for Socialist Studies 3(2):7-30.

Smith, Dorothy E. 2008. "From the 14th Floor to the Sidewalk: Writing Sociology at Ground Level." Sociological Inquiry 78(3):417-422.

Smith, George. 2006. “Political Activist as Ethnographer." Pp 44-70 in Sociology for Changing the World, edited by C. Frampton et al. Black Point: Fernwood.

Sobo, Elisa J., Candice Bowman, and Allen L. Gifford. 2008. "Behind the Scenes in Health Care Improvement: The Complex Structures and Emergent Strategies of Implementation Science." Social Science \& Medicine 67(10):1530-1540.

Stooke, Roz and Pamela J. McKenzie. 2009. “Leisure and Work in Library and Community Programs for Very Young Children." Library Trends 57(4):657-675.

Taber, Nancy. 2010. “Institutional Ethnography, Autoethnography, and Narrative: An Argument for Incorporating Multiple Methodologies." Qualitative Research 10(1):5-25.

Tarasuk, Valerie and Joan M. Eakin. 2005. "Food Assistance through 'Surplus' Food: Insights from an Ethnographic Study of Food Bank Work." Agriculture and Human Values 22(2):177-186.

Taylor, Evan T. 2013. “Transmen's Health Care Experiences: Ethical Social Work Practice Beyond the Binary." Journal of Gay \& Lesbian Social Services: The Quarterly Journal of Community \& Clinical Practice 25(1):102-120.
Townsend, Elizabeth. 2003. "Reflections on Power and Justice in Enabling Occupation." Canadian Journal of Occupational Therapy 70(2):74-87.

Townsend, Elizabeth et al. 2006. “Effects of Workplace Policy on Continuing Professional Development: The Case of Occupational Therapy in Nova Scotia, Canada." Canadian Journal of Occupational Therapy 73(2):98-108.

Traverso-Yepez, Martha. 2009. “The Difficulties of Dealing with Social Inequities at the Family Health Program in Natal, Brazil." Critical Public Health 19(2):193-202.

Truman, Carole. 2003. “Ethics and the Ruling Relations of Research Production." Sociological Research 8(1). Retrieved July 19, 2013 (http://www.socresonline.org.uk/8/1/truman.html).

Tummons, Jonathan. 2010. "Institutional Ethnography and Actor-Network Theory: A Framework for Researching the Assessment of Trainee Teachers." Ethnography and Education 5(3):345-357.

Veras, Renata Meira and Martha Traverso-Yepez. 2011. “The Kangaroo Program at a Brazilian Maternity Hospital: The Preterm/Low-Weight Babies' Health-Care Under Examination." Nursing Inquiry 18(1):84-91.

Walby, Kevin. 2005. "How Closed-Circuit Television Surveillance Organizes the Social: An Institutional Ethnography." $\mathrm{Ca}$ nadian Journal of Sociology 30(2):189-214.

Walby, Kevin. 2006. “Locating Televisual and Non-Televisual Textual Sequences with Institutional Ethnography: A Study of Campus and Apartment CCTV Security Work." Culture and Organization 12(2):153-168.

Walby, Kevin. 2007. "On the Social Relations of Research: A Critical Assessment of Institutional Ethnography." Qualitative Inquiry 13(7):1008-1030.

Walby, Kevin. 2013. “Institutional Ethnography and Data Analysis: Making Sense of Data Dialogues." International Journal of Social Research Methodology: Theory \& Practice 16(2):141-154.

Watson Stephen J., Daniel J.Zizzo, and Piers Fleming. 2015. “Determinants of Unlawful File Sharing: A Scoping Review." Retrieved May 20, 2015 (http://dx.doi.org/10.1371/journal.pone.0127921).

Webster, Fiona et al. 2015. “An Institutional Ethnography of Chronic Pain Management in Family Medicine (COPE) Study Protocol." BMC Health Services Research 15:494.

Weigt, Jill. 2006. “Compromises to Carework: The Social Organization of Mothers' Experiences in the Low-Wage Labor Market after Welfare Reform." Social Problems 53(3):332-351.

Widerberg, Karin. 2004. "Institutional Ethnography-Towards a Productive Sociology: An Interview with Dorothy E. Smith." Sosiologisk Tidskrift 12(2). Retrieved July 06, 2014 (http://www. uio.no/studier/emner/sv/iss/SOS4000/v06/forelesningsnotater/ Karin\%20Widerberg\%20intervju\%20med\%20Dorothy\%20 Smith.doc.).

Winfield, Bonnie M. 2003. “Turning the Kaleidoscope: Telling Stories in Rhetorical Spaces." Journal of Sociology and Social Welfare 30(1):23-40.

Winkelman, Warren J. and Nancy V. Davis Halifax. 2007 "Power Is Only Skin Deep: An Institutional Ethnography of Nurse-Driven Outpatient Psoriasis Treatment in the Era of Clinic Web Sites." Journal of Medical Systems 31(2):131-139.

Wittman, Amanda. 2010. “Looking Local, Finding Global: Paradoxes of Gender Mainstreaming in the Scottish Executive." Review of International Studies 36(1):51-76.

Yan, Miu Chung. 2003. “Antiracism Discourse: The Ideologica Circle in a Child World." Journal of Sociology and Social Welfare 30(1):127-144.

Malachowski, Cindy, Christin Skorobohacz, and Elaine Stasinlis. 2017. "Instittionat thnography as a Method of he A Scoping Review." Qualitative Sociology Review 13(4):84-121. Retrieved Month, Year (http://www.qualitativesociologyreview. org/ENG/archive_eng.php). 